IZA DP No. 6946

The Economic Security Index:

A New Measure for Research and Policy Analysis

Jacob S. Hacker

Gregory Huber

Austin Nichols

Philipp Rehm
Mark Schlesinger

Robert G. Valletta

Stuart Craig

October 2012 


\title{
The Economic Security Index: A New Measure for Research and Policy Analysis
}

\author{
Jacob S. Hacker \\ Yale University \\ Gregory Huber \\ Yale University \\ Austin Nichols \\ Urban Institute \\ Philipp Rehm \\ Ohio State University
}

\author{
Mark Schlesinger \\ Yale University
}

Robert G. Valletta

Federal Reserve Bank of San Francisco

and IZA

Stuart Craig

Yale University

Discussion Paper No. 6946

October 2012

\author{
IZA \\ P.O. Box 7240 \\ 53072 Bonn \\ Germany \\ Phone: $+49-228-3894-0$ \\ Fax: +49-228-3894-180 \\ E-mail: iza@iza.org
}

\begin{abstract}
Any opinions expressed here are those of the author(s) and not those of IZA. Research published in this series may include views on policy, but the institute itself takes no institutional policy positions. The IZA research network is committed to the IZA Guiding Principles of Research Integrity.

The Institute for the Study of Labor (IZA) in Bonn is a local and virtual international research center and a place of communication between science, politics and business. IZA is an independent nonprofit organization supported by Deutsche Post Foundation. The center is associated with the University of Bonn and offers a stimulating research environment through its international network, workshops and conferences, data service, project support, research visits and doctoral program. IZA engages in (i) original and internationally competitive research in all fields of labor economics, (ii) development of policy concepts, and (iii) dissemination of research results and concepts to the interested public.
\end{abstract}

IZA Discussion Papers often represent preliminary work and are circulated to encourage discussion. Citation of such a paper should account for its provisional character. A revised version may be available directly from the author. 
IZA Discussion Paper No. 6946

October 2012

\section{ABSTRACT}

\section{The Economic Security Index: A New Measure for Research and Policy Analysis}

This paper presents the Economic Security Index (ESI), a new, more comprehensive measure of economic insecurity. By combining data from multiple surveys, we create an integrated measure of volatility in available household resources, accounting for fluctuations in income and out-of-pocket medical expenses, as well as financial wealth sufficient to buffer against these shocks. We find that insecurity has risen steadily since the mid-1980s for virtually all subgroups of Americans, albeit with cyclical ups and downs. We also find, however, that there is substantial disparity in the degree to which different groups are exposed to economic risk. As the ESI derives from a data-independent conceptual foundation, it can be measured using different data sources. We find that the degree and disparity by which insecurity has risen is robust across these sources.

JEL Classification: I14, D31, J11

Keywords: household income, volatility, wealth, medical spending

Corresponding author:

Robert G. Valletta

Federal Reserve Bank of San Francisco

101 Market Street

San Francisco, CA 94105

USA

E-mail: rob.valletta@sf.frb.org 
The Economic Security Index (ESI) is a new measure of economic security designed to foster research and policy analysis. Using a simple definition of economic security and measured using U.S. panel economic data, the ESI provides a new perspective on the dimensions, distribution, and development of American economic security.

This article focuses on the motivation and design of the ESI and the issues that it raises for theory and research. The ESI represents the first attempt to incorporate into a single unified measure several key influences on economic security, namely income loss, medical spending shocks, and the buffering effects of financial wealth. It focuses on one of the most fundamental elements of economic security — the degree to which individuals experience and are protected against large economic losses arising due to income volatility or nondiscretionary spending. Accordingly, the ESI is based on panel data regarding individual economic experiences, rather than public opinion data regarding individuals' perceptions of those experiences. While this is only a partial representation of insecurity, the index provides a revealing picture of the varied exposure of Americans to volatile economic circumstances over time and across subgroups of the population.

The remainder of this article is structured as follows. The first section briefly takes up prior research on economic security. The second discusses the design considerations involved in analyzing the major components of the ESI: income losses, medical spending dynamics, and wealth holdings. The third discusses the data sources relied on, their strengths and limitations, and the analytic choices required to use them in an unbiased fashion. The fourth section presents the basic findings, charting both over-time trends and variation in insecurity across major groups using two alternative datasets: matched data from the March Current Population Survey (CPS) and sequential mini-panels from the Survey of Income and Program Participation (SIPP). The 
section also compares these results with a more limited index of income loss based on the Panel Study of Income Dynamics (PSID), showing substantially similar (upward) trends and cyclical variations across all three sources. The article concludes by outlining some of the main empirical and theoretical issues that the ESI raises for future research.

\section{Prior Research on Economic Security}

The basis for concern about economic security is the belief that uncertain economic prospects leave people worse off. This belief has two logical foundations: that individuals fear large economic losses, and that when individuals experience such losses without sufficient buffering, they suffer hardship, particularly (but not only) if those losses are unexpected. A growing body of theoretical and empirical research has investigated both foundations. Scholars in an array of disciplines - from economics and political science to social psychology and sociology — have demonstrated the impact of income instability ${ }^{1}$ and perceived insecurity on individual well-being, ${ }^{2}$ labor market behaviors, ${ }^{3}$ savings aspirations, ${ }^{4}$ and political attitudes. ${ }^{5}$

This growing body of research suggests that economic insecurity is rooted in three basic features of human cognition and market dynamics. The first is the fundamental behavioral trait known as "loss aversion," the tendency for individuals to be more sensitive to reductions in their economic standing than to increases ${ }^{6}$. The second is the difficulty people face when assessing relevant economic contingencies, which makes it difficult for people to appropriately assess and

\footnotetext{
${ }^{1}$ Nichols(2008), Hacker, (2008).

2 Miron-Shatz (2009), Graham and Pettinato(2002), Michalos et al. (2007).

${ }^{3}$ Stephens (2002).

${ }^{4}$ Nichols and Favreault(2009); Carroll, Dynan, and Krane (2003).

${ }^{5}$ Hacker, Rehm, and Schlesinger (2013), Rehm, Hacker, and Schlesinger (2012), Rehm (2009), Cusack, Iversen, and Rehm (2006), Mughan and Lacy (2002).

${ }^{6}$ Fellner and Sutter (2009), Kahneman and Tversky (1979).
} 
safeguard themselves against the most serious risks they face ${ }^{7}$. The third is the incomplete character of many private insurance markets, as well as stark differences in personal and familial capacity based on wealth adequacy, credit access, and the character of social networks, for insuring against those contingencies. ${ }^{8}$

Much of the existing empirical research adopts a common, though often implicit, definition of economic security: the degree to which individuals are protected against hardshipcausing economic losses. Yet there is much less agreement on how to translate this general definition into specific domains or how to conceive of the interplay of multiple economic risks, and even less on how to measure the actual extent of protection that people enjoy. ${ }^{9}$

Three main approaches can be found in existing research. The first uses a weighted index of multiple measures (e.g., Osberg and Sharpe 2005), which captures multiple dimensions. These indices can draw from multiple data sources, but are sensitive to which measures are included and how they are weighted. Unfortunately, theory provides limited guidance about how to weight these difference measures, in part because of the paucity of research looking at the interaction of and relative impact of different economic risks. By adopting a "named-risk" approach (Osberg and Sharpe 2005), these approaches also essentially fix the roster of economic risks at a point in time (as well as assume this roster is the same across different subgroups), rather than allowing a changing mix of risks to household finances to be considered as the threats to economic security over the years under study (or across different groups).

The second approach is to measure resource adequacy or asset sufficiency (e.g. Lusardi et al. 2011). The level of resources or wealth clearly plays a major role in economic insecurity, and

\footnotetext{
${ }^{7}$ Difficulties may be cognitive—e.g. Sunstein (2002), Quartz (2009), Slovic (2000)—or informational as in Dickens (1984).

${ }^{8}$ Kahneman, Knetsch, and Thaler (1991), Winkelman and Winkelman (1998), Ligon and Schechter (2003) Bénabou and Ok(2001), Agell (1999).

${ }^{9}$ For a sense of the disagreements, see Davis (2008), Stephens (2001), Gruber (2001).
} 
this approach has the advantages of simplicity and reliance on a single data source. Such indices, however, are better understood as measures of the resource level or buffering capacity of an individual, rather than a measure of realized security or insecurity. In particular, adequacy measures do not capture the likelihood an individual will suffer a reversal and need to draw on wealth or resources—a probability that may vary both over time and across individuals. Realized insecurity requires the coincidence of inadequate buffers and the actual experience of economic loss.

The third approach veers in the other direction and measures income or expenditure volatility. This is a measure fundamental to risk or insecurity, which helps explain why the literature on earnings, household income, and consumption volatility is large and growing. ${ }^{10}$ However, observed variability in income fails to account for two critical dimensions of insecurity: the risk of large, involuntary expenditures—such as medical out-of-pocket expenditures (MOOP) — and the capacity of individuals or households to use their wealth to reduce the effect of income changes on consumption, both of which influence American's concerns about their economic prospects (see Hacker et al, 2013).

The ESI builds on these three approaches while addressing some of the key shortcomings of each. In particular, the index grows out of and extends the recent wave of research on household income variability. However, the ESI incorporates a broader set of influences on family economic well-being than income fluctuations alone, and it is designed to respond to a number of sensible critiques of research on income instability. At the same time, the ESI is designed to be a simple, consistent measure that is simultaneously easy to understand and sophisticated enough to provide a foundation for further research.

\footnotetext{
${ }^{10}$ See for recent work and detailed reviews of past work Nichols and Zimmerman, 2008; Nichols, 2008; Gottschalk and Moffitt, 2009; Dynan, Elmendorf, and Sichel, 2008; Hacker and Jacobs, 2008; Gorbachev, 2011.
} 


\section{Design Considerations}

The ESI is an annual index that represents the share of individuals who experience at least a 25 percent decline in their inflation-adjusted “available household income” from one year to the next (except when entering retirement) and who lack an adequate financial safety net to replace this lost income until it returns to its original level. More formally, for each year $t$,

1. $E S I_{t}=\frac{\sum L_{i t}}{n_{t}}$, which is the proportion of individuals who experience loss L, defined as 2. $L_{i t}=\left(\frac{y_{i t}-M_{i t}-D_{i t}}{e_{i t}}<\left(\frac{3}{4}\right) \frac{y_{i t-1}-M_{i t-1}-D_{i t-1}}{e_{i t-1}}\right)\left(W_{i t}<W_{i t}^{*}\right)\left(1-R_{i t}\right)$.

\section{Definitions}

a) $y_{i}$ is total household income

b) $M_{i}$ is household out-of-pocket medical spending

c) $D_{i}$ is the annual household debt service burden

d) $e_{i}=\left(0.7\left(\text { children }_{i}+\text { adults }_{i}\right)\right)^{\wedge} 0.7$ represents a family size equivalence scale, which gives less weight to children and assumes a concave relationship between household size and needs, and

e) The last two terms in equation 2 are dichotomous indicators for lacking sufficient financial wealth $\left(W_{i t}<W_{i t}^{*}\right)$ and not transitioning into retirement $\left(1-R_{i t}\right)$, on the assumption that working-age people with large liquid wealth holdings (defined shortly) and exiting the labor force do not experience 25 percent or greater losses as insecurity in the same way other individuals do. 
To be clear, the ESI represents the share of individuals experiencing large losses, although these losses are based on the household experience. The rate of unbuffered losses, or mean $\mathrm{L}$ (equation 1), represents the risk of unbuffered loss in that population or subpopulation.

We cannot identify the expected risk of such losses for any one person in any year. That is, $L$ is the realization of the risk rather than the risk itself. For this reason, we cannot think of cases with $L=1$ as "insecure" and those with $L=0$ as "secure." Instead, we use the rate within a group to characterize that group’s risk of loss, or economic insecurity. Put another way, we will say that an individual whose group’s risk of loss L increased from 20 to 25 percent across two periods has experienced an increase in economic insecurity even if that individual did not experience a loss $\mathrm{L}$ in either period. In what follows, we consider both the population-wide risk of loss (i.e., the risk among residents of the United States) and the risk of loss within subgroups defined by race, education, and other traits.

\section{Components of the ESI}

The ESI provides a picture of three important features of Americans’ unstable economic circumstances: the probability of large household income declines, the possibility of large medical-out-of-pocket (MOOP) spending shocks, and the capacity of households to buffer these economic events by spending down liquid financial wealth. These (along with retirement) are the economic risks that Americans are most worried about in the survey context, and they are also the risks that individuals believe are most beyond individual control . ${ }^{11}$

For both simplicity of exposition and because a percentage loss measure is inherently scaled to income, the 25 percent threshold does not vary with household income or other

\footnotetext{
${ }^{11}$ See Hacker, Rehm, and Schlesinger (2010) and Hacker et al. (2010).
} 
individual or household characteristics. Substantial evidence suggests that the median American household would have considerable difficulty making ends meet if it experienced an income loss of 25 percent or larger. While developing the ESI, we assessed Americans' perceptions of economic security using a new set of opinion polls embedded in the American National Election Study (hereinafter ANES, Hacker, Rehm, and Schlesinger 2010, 2013). Although the ANES findings are not directly incorporated into the ESI—which is based entirely on realized economic losses - they inform elements of its design and provide a means of validating ESI estimates for 2008 and 2009. The ANES findings suggest that the 25 percent threshold is a very reasonable standard. When asked how long their household could go without its current income before experiencing hardship, for example, just under half of respondents to the ANES survey indicated that their household could go two months or less. The loss of three months of income (that is, 25 percent of annual income) would therefore be expected to cause hardship for at least half of Americans. ${ }^{12}$

While income drops have a direct relation to economic security, for several reasons they are not synonymous with it. First, shocks induced by nondiscretionary spending obligations can also pose substantial threats to economic security that are not captured by fluctuations in income alone. ${ }^{13}$ Perhaps the most important of these nondiscretionary expenses is medical care. Fifteen years ago, the National Academy of Sciences (NAS) recommended that the burden of medical out-of-pocket expenses should be incorporated into the determination of poverty status, because medical spending reduces income available for other purposes. ${ }^{14}$ The ESI incorporates this recommendation by reducing available household income by the amount of MOOP spending. As

\footnotetext{
${ }^{12}$ It is worth noting that our findings are not sensitive to this choice- - thresholds of 10 or 50 percent yield similar upward trends of insecurity.

${ }^{13}$ Collins et al. (2008); Dynan and Kohn (2007); Kusnet, Mishel, and Teixeira (2006).

${ }^{14}$ Citro and Michael (1995); see also Burtless and Siegel (2001)..
} 
a result, the ESI's measure of available household income may drop not only because of declines in earnings or other income, but also due to increases in MOOP spending or some combination of the two. The ESI therefore treats MOOP as a constraint on alternative spending that reduces available family income. MOOP includes insurance payments; doctor, dentist, and hospital fees; and prescription drugs and durable medical equipment, so long as these costs are paid by individuals directly rather than by insurance or other payers.

Second, the extent to which drops in earnings are associated with hardship also depends on household characteristics and the availability of public and private transfers. Households with multiple earners have the capacity to buffer reductions in earnings or increased nondiscretionary needs for one household member through compensatory responses by other members of the household, such as an increase in hours worked. ${ }^{15}$ Similarly, access to public transfers (such as unemployment insurance) or private transfers (such as gifts from relatives) can offset earnings declines, reducing the impact of such declines on income.

The ESI incorporates these buffers in two ways: (1) by adopting as broad as possible a definition of income and (2) by focusing on individuals' household income, adjusted for household size. Briefly, the measure of income used for the ESI includes earned income, property and asset income, cash transfer payments (including private transfers, such as gifts), private pension payments, unemployment benefits, lump-sum and one-time payments, and regular salary or other income from a self-owned business.

\footnotetext{
${ }^{15}$ Stephens (2002), Attewell (1999), Edin and Lein (1997). Risk buffering within the nuclear family/household does not take into account the extensive income transfers that occur within extended families, both as caregivers and as sources of financial succor in hard economic times. In the ANES survey, roughly 20 percent of all respondents reported making a substantial financial payment to help out a member of their extended family. When asked if they could borrow money from their extended family to meet essential household expenditures, 54 percent indicated that they could, with a median largest amount that could be borrowed of about $\$ 10,000$.
} 
Available family income is also reduced by the estimated cost of debt-service for families with negative financial wealth holdings. Unlike most other expenditures, debt-service is nonadjustable in the sense that, although the time horizon for payment may be flexible, individuals cannot change past expenditures. Symmetric with our treatment of housing wealth and other illiquid assets (as discussed below), we only include unsecured debt in our calculation. The main effect on the ESI of this adjustment comes through its alteration of the income "base" from which large drops occur. Decreasing income by estimated debt service makes drops of a given absolute magnitude larger as a share of income. Debt service is not calculated for individuals with positive net financial wealth because the assumption is that any outstanding debts could be paid off using available wealth.

Income is aggregated at the household level and adjusted for family size using the NASrecommended equivalence scale for the poverty line. The NAS-recommended equivalence scale, given in definition $d$, adjusts income by a factor that assumes a concave relationship between household size and needs and gives less weight to children. ${ }^{16}$ This adjustment creates a measure of income that is sensitive to changes in household resources as well as size. For example, a family with a stable income may register as experiencing a loss simply because of the addition of a child to the household. Similarly, a household in which one earner dies may be spared a loss because the household's needs also declines simultaneously. ${ }^{17}$

\footnotetext{
${ }^{16}$ The NAS recommended equivalence scale is from Citro and Michael (1995). See also Expert Group on Household Income Statistics (2001).

${ }^{17}$ While some changes in family size may reflect choices (e.g., divorce, marriage, a planned child), others are less voluntary (death of a spouse, etc.). While adjustment for family size is theoretically important when measuring household resources, multiple sensitivity tests indicate that it only affects the level of the index to a small degree. The overall level and trend in the ESI is similar if we exclude all households that experience changes in family size as well (See figure 1).
} 
Finally, the impact of economic fluctuations depends in part on the extent to which these changes can be anticipated and adapted to before their occurrence. ${ }^{18}$ The ESI focuses on risks that, according to our survey, Americans believe are difficult to anticipate and prepare for (Hacker, Rehm, and Schlesinger 2010). But even substantial unanticipated drops in income may not result in material hardship if a household has sufficient precautionary savings to buffer the decline. $^{19}$

Defining sufficient precautionary savings—-the "adequate financial safety net" of the definition that opened this section—has two aspects. The first is deciding what constitutes precautionary savings. The ESI focuses on "liquid financial wealth,” that is, wealth that can be easily accessed to replace lost income. In practice, this is all wealth holdings besides the primary home, personal vehicles, and earmarked retirement savings. While housing is the main form of wealth held by most Americans, owner-occupied homes have substantial use value: being forced to sell a home after a job loss would, by most definitions, constitute a form of insecurity. Nor is it clear that those who experience large available income losses could easily extract large sums from their home by taking on additional debt—either because their status (e.g., unemployed) would make them poor credit risks or because, in certain subsets of the period studied (e.g., 2008 on) credit markets tightened substantially. Moreover, as the recent financial crisis reveals, housing debt constrains family finances just as other forms of debt do, creating the risk of delinquency, impairment of access to credit, and property loss. ${ }^{20}$

\footnotetext{
${ }^{18}$ Japelli and Pistaferri (2010); Diener, Lucas, and Scollon, (2006), Ligon and Schechter (2003).

${ }^{19}$ See Japelli and Pistaferri, 2010; Stephens (2001).

${ }^{20}$ Although the theoretical grounds for excluding housing wealth from our financial safety net measure are strong, we did assess the effect of incorporating housing wealth into the index. As a sensitivity test, the ESI was recalculated with owner-occupied home equity treated as a source of additional income (much like a retirement annuity) over the course of a house's mortgage. The idea is that rising home values provide families with a means of consuming at a higher level than their income alone would allow-a treatment congruent with the way in which economic analyses of recent years have studied the consumption effects of housing wealth. This sensitivity analysis showed that the ESI is only modestly reduced by the inclusion of housing wealth over the 1985-2007 period. This
} 
The second aspect of incorporating wealth is determining what level of wealth holdings is sufficient to buffer income losses. The ESI defines an "adequate financial safety net” as liquid financial wealth sufficient to replace lost income for the typical duration and magnitude of loss experienced prior to a return to pre-drop income. Thus, individuals who experience a 25 percent or greater household income loss are not counted as "insecure" if they have liquid financial wealth equal to or greater than the cumulative loss for the median individual with their sociodemographic characteristics who also experience such a loss

Of course, this wealth threshold may be too low, because families that fully deplete their wealth in response to a shock are more vulnerable to hardship during subsequent shocks. Moreover, some families will not return to their pre-drop income within the typical duration to recovery, and some will never return. Their arguably disproportionate hardship is not captured by the median loss experience. Alternatively, this wealth threshold may be too high, because households that face permanent changes in their income, rather than transitory shocks, may reduce their future consumption. Still, even if households can or should adjust their consumption, they are nonetheless experiencing a large shock to income that is likely to induce hardship. Indeed, it is these households for whom income shocks are arguably most devastating. Focusing on the median recovery duration of similar individuals provides us with some notion of an individual's expectation of recovery and hence of typical required precautionary savings levels needed to fully offset a large shock to income.

Related to the issue of anticipation, retirement is an economic transition for which declines in income are not only expected, but are to some extent matched by declines in

potentially surprising finding reflects the reality that housing debt rose roughly in tandem with housing wealth over this period. Of course, if housing wealth were incorporated into the calculation of the ESI, the spike in economic insecurity would be even higher in the current period, given the large drop in home prices and the rising prevalence of negative homeowner equity that has occurred in the last three years. 
nondiscretionary spending. ${ }^{21}$ For this reason, those entering retirement are excluded from the count of the insecure even if available household income declines by 25 percent or more ${ }^{22}$.

\section{Data Considerations}

Because the ESI is based on individual-level experience of large available income declines from one year to the next, it requires a panel survey that follows individuals over time. We present the ESI as constructed from two separate surveys: the Survey of Income and Program Participation (SIPP) and the March Supplement to the Current Population Survey (CPS). Each survey has its own set of strengths and weaknesses for analyzing insecurity. The most recently released series of the index was calculated using the CPS. Because not all of the data required to calculate the index are available from these core surveys, however, the ESI also relies on two additional data sources: the Panel Study of Income Dynamics (PSID) and the Consumer Expenditure Survey (CEX). In addition, we assess the robustness of the over-time trend in the index by looking at the income-loss component of the ESI (that is, without accounting for medical costs or wealth adequacy) using the Panel Study of Income Dyanamics.

\section{Structure and use of the SIPP and the CPS}

The first survey we use to examine household income dynamics is the Survey of Income and Program Participation. The SIPP consists of a series of short-term panels with quarterly interviews, the first of which began in 1984. Each panel is a nationally representative, stratified

\footnotetext{
${ }^{21}$ However, the exact timing of retirement is frequently influenced by factors that are not as easily anticipated, such as job loss and changes in health status, and there remains dispute about exactly how large a share of pre-retirement income individuals need in retirement.

${ }^{22}$ It should be noted that this exclusion accounts for only roughly 2-3 percent of the sample in any given year and affects the level of, and trend in, the index only to a very small degree (see figure 2)
} 
sample with an overlapping panel design used prior to 1996 and non-overlapping panels used from that point on. The reference period for each interview is the four month period preceding the interview month, with income recorded for each month separately. The interviews are spread across four rotation groups, with one-quarter of the interviews conducted in each month. The survey generally was administered beginning in the February of each year for the 1985 through 1993 panels and 2001-2004 panels, beginning in October 1983 for the 1984 panel, and April 1996 for the 1996 panel. Prior to 1992, each panel typically had 8 waves, the 1992-93 and 2001 panels had 9 waves, and the 1996 and 2004 panels had 12. For the 2008 panel, 7 waves are currently available, allowing for analysis of individuals for periods ranging from 2 to 4 years and enabling short-run panel analyses over an extended timeframe.

The second primary survey used, the Current Population Survey, is not designed to be used as a traditional panel survey. Instead, it is a series of cross-sections in which individuals can be matched from one year to the next because of its rotating sample. The CPS is a survey of geographic residences, which are sampled and interviewed over a period of about a year and a half regardless of the current occupant. Because the March survey is repeated a year later, however, it is possible to trace a subset of individuals from one year's survey to the next if the individuals are living in the same housing unit in March of both years.

The SIPP and CPS each have their advantages and limitations. In many ways, the SIPP is particularly well suited for examining income instability: Its traditional panel structure and 3-4 year panels allow for the measurement of prevalence and persistence of economic loss. Additionally, the intentional panel structure allows for the tracking of individuals who change residence from year-to-year. The SIPP also provides more complete and direct estimates of 
wealth and, to a lesser degree, medical spending, than does the CPS or even the Panel Study of Income Dynamics.

Yet the limitations are substantial as well. The SIPP consists of a series of short-term panels between which there exist gaps in data that cannot be filled. One of these gaps overlaps with the onset of the recent recession in 2007-2009, which makes it impossible to use the SIPP to examine annual increases in economic insecurity between 2007 and 2010. ${ }^{23}$ By contrast, the matched CPS data allow for consistent investigation of year-to-year changes; our current series has only one gap, in 1995, when the redesigned survey was fielded with a fresh sample that could not be matched across years. Although individuals can be followed for only two years, the linked CPS is well-suited for the ESI's focus on year-to-year changes in income and other household resources. Unlike the SIPP, moreover, the CPS goes back before the mid-1980s. Future work will use the earlier CPS data to estimate insecurity in earlier years.

Moreover, the SIPP panels feature a relatively high "attrition rate" — that is, people exiting the survey over time. Because the panels last as long as four years, such attrition can have substantial effects on the characteristics of those included in the survey. In particular, attrition may reduce the estimated level of insecurity in the SIPP toward the end of each panel, because those with more volatile incomes are more likely to drop out of the panel. By contrast, the linked CPS data always provide panels covering the same span of time-two years—so the effect of attrition is both less pronounced and more or less constant from year to year.

The CPS has other advantages as well. It is a larger dataset than the SIPP and, unlike the SIPP, designed to be used for the analysis of individual states as well as the nation as a whole,

\footnotetext{
${ }^{23}$ The 2004 SIPP data ended in 2007 and the first year of data in the 2008 SIPP panel runs from mid-2008 to mid2009, with a large gap in 2008. Job losses that happened during 2008 would not be reflected in income changes from the first year to 2009-2010. Job losses accelerated through 2008, with new unemployment claims peaking in January 2009. Thus the SIPP data misses the spike of job losses in 2008.
} 
allowing for analyses of regional and state differences in economic security within the United States.

The main drawback of using the CPS for examining changes in income from one year to the next is that the CPS is a survey of geographic residences, rather than households, so people who change residences cannot be followed. However, our original data source, the SIPP, shows that excluding the modest share (10-15 percent) of individuals who change residences in any given year has little effect on the ESI. People who move have more unstable incomes than those who do not, so our new estimates may understate the true level of insecurity. But, according to our investigations, the bias is small—less than a percentage-point reduction in the index. Furthermore, we developed a refined approach for linking individuals across survey years that provides high confidence in our year-to-year comparisons. ${ }^{24}$

For all these reasons, we believe the CPS is the better source for an annual index. The crucial point, however, is that while level of the ESI derived from the CPS is slightly higher than the level of the ESI derived from the SIPP, the trend over time and the differences across groups are very similar. Moreover, as we will show after introducing these two series, both the CPSbased and the SIPP-based indices match levels of and trends in income instability in the Panel Study of Income Dynamics (PSID) relatively closely as well.

\section{Measuring year-to-year income}

\footnotetext{
${ }^{24}$ A developed literature exists describing methods for obtaining year-to-year matches in the CPS (e.g., see Madrian and Lefgren, 2000; Feng, 2001; Feng, 2008), which typically involve matching based on identifiers and subsequently invalidating matches based on discrepancies in demographic characteristics. For a variety of reasons, we employ a distance-based matching method which allows individuals' within household identifiers to vary across years. For more information regarding this approach see Hacker et al., 2011. Matches can be made for all years from 1986 through 2010 except for 1995, because household identifiers changed in that year. Additionally, we construct longitudinal weights using propensity scores, adjusting for age, race, sex, and state of residence to match the distribution of the full year- 2 sample. These weights also provide us with the opportunity to correct for the extent to which individuals with imputed income components vary on observable characteristics.
} 
The ESI's measure of income is household gross money income, which includes earned income (wage and salary income from employment), property and asset income, cash transfer payments (AFDC/TANF, SSI, Social Security, unemployment benefits, and veteran's payments), lump-sum and one-time payments (e.g., inheritances, insurance settlements, retirement distributions), and regular salary or other income from a self-owned business. Because both actual tax liabilities and the information necessary to simulate tax burdens are not consistently available in the data, the ESI does not subtract taxes from available family income. ${ }^{25}$

The CPS income questions, asked in March, refer to income in the previous calendar year. In the SIPP, data are aggregated into annual observations from the monthly data. The SIPP rotation schedule means that the specific 12 months depend on the individual's rotation group. Thus, all observations coded as a single year will span a 15-month period that generally ranges from October of the year preceding the observation year through December of the observation year. The exception is the 1996 survey, for which the April start date implies that the annual observations refer to periods covering December of the preceding year through February of the year after the observation year. (The same is true of the 1984 panel, where the first reference month was June of 1983, but we do not use it in these estimations.) Annual values of the variables are formed by summing the reported values for the 12 reference months from the 3 relevant waves (e.g., for income) or taking the end-period value or average across the 3 waves (e.g., for household characteristics such as size, individual characteristics such as age, etc.). This extract enables examination of changes in income and related variables between consecutive years for all years from 1985 to 2007, with the exception of years at the start of non-overlapping panels (1990, 1996, 2001, 2004 and 2008) and years in which the available information on

\footnotetext{
${ }^{25}$ Previous research has imputed values for taxes and tax credits, which affects the level but does not dramatically alter the trend of income volatility (Nichols 2008). Future work, focusing on an international comparison, will explore the impact of taxes on insecurity.
} 
income or wealth was insufficient to form the ESI's measure of available income (1989 and 2000).

The ESI analyses rely on the matching of consecutive observations on annual income (and related variables such as medical spending). For SIPP panels with only 8 waves rather than 9 or 12, the final year of data is incomplete. Similarly, individuals who leave the sample prior to panel completion often have fewer than 12 months of data available in a given year. To account for sample changes related to these factors and to ensure consistent measurement of annual income over time, the analysis sample is restricted to individuals in households with 12 complete monthly observations of income in the reference year. These income data are weighted using annual sampling weights provided in the survey that are designed to adjust the sample for nonrandom attrition across selected population groups (as opposed to the standard survey weights defined for each wave of data, which are appropriate for point-in-time estimates of population characteristics).

\section{Treatment of imputed income values}

In large household surveys like the SIPP and CPS, direct responses regarding key variables such as income and wealth often go unreported. Under these circumstances, it is common to apply standardized imputation procedures for filling in missing values. As has been noted in other recent work (e.g., CBO 2008), the incidence of imputation of key income components in the SIPP has been rising. Census Bureau imputation procedures often match individuals with missing data (“recipients”) to “donors” with similar characteristics. The donor’s response is then used to fill in the missing value for the recipient. This procedure is referred to as "hot deck" imputation. Because it is not possible to guarantee that such matches accurately 
reflect the income received by the individual who did not report it, use of imputed values can impart spurious volatility to measured changes in recorded annual income.

In addition to hot deck imputation, each survey also subjects its data to an additional imputation procedure. In the CPS this is called a whole imputation, which occurs when an individual responds to the basic March monthly CPS survey, but for whatever reason fails to complete the supplement. Under these circumstances, the Census Bureau applies an imputation technique similar to the hot deck, except instead of imputing income, an entire household record based on demographic characteristics in the basic file is imputed. Inclusion of these individuals is problematic in the same way as hot deck imputation cases.

While the rising incidence of imputation in the SIPP has been noted by others, changes in the form of imputation have not. Prior to the 1996 survey, the Census Bureau relied primarily on hot deck imputation. Beginning with the 1996 panel, however, longitudinal imputation methods were adopted on a widespread basis. These methods entail either carrying over previous month income values to months with missing data or matching individuals based on income in prior months or waves. In contrast to hot deck imputation, which may exaggerate income volatility, longitudinal imputation is likely to impart a high degree of stability to income values over time.

Given the potential for artificial instability introduced by observations that rely on hotdeck or similar imputations and the absence of this problem for observations that rely on longitudinal imputation, observations in the SIPP with hot deck imputations of the primary components of household income were eliminated, while observations with longitudinal imputations were retained. Keeping the latter observations is preferable to dropping them for two reasons. First, while longitudinal imputations may introduce some artificial stability, such imputation is designed to make as limited as assumptions as possible, simply carrying income or 
its components across observations. Second, in analyses of income volatility, limiting the sample based on the completeness of data-unless, as in hot-deck imputation, absolutely necessarycarries the serious risk of excluding individuals with unstable economic circumstances, since the reporting of income and other variables is likely to be less complete for such individuals.

In the CPS, observations with hot decked primary components and those that are wholly imputed are excluded. The primary components are the wage and salary earnings and business income of the household head and spouse. On average, these sources of income account for about 70 percent of total household income, with the remaining share of total household income mostly spread across earnings by other individuals and various sources of unearned income. In the SIPP, imputed values can arise for any of the 12 months of data corresponding to an annual observation. An observation is classified as imputed if any of the 12 monthly observations on any of the four primary income components are imputed. Any observation for which these income components were hot deck imputed in either year were eliminated from the calculation of income change. Similarly, an observation is excluded from the CPS sample if imputation occurs in either year.

Figure 3 shows imputation rates by year (unweighted), decomposed into any months of imputation (all types), any months of hot deck imputation (can include longitudinal imputations for some months in the year), and any months of longitudinal imputation (not hot deck) for any of the four primary income components; the tabulations indicate the percentage of observations on income changes that would be affected by imputation. The values in the "any" and "hot deck" columns are identical prior to 1996 in the SIPP and 1991 in the CPS. SIPP imputation rates rose noticeably after 1995, but the increase arose primarily from reliance on longitudinal imputation, with hot deck imputation rates dropping substantially. While the incidence of hot deck item 
imputation has risen in the CPS over the series, whole imputation has been fairly constant, affecting roughly 10-15 percent since it began in 1989 .

[Figure 3 Here]

\section{Accounting for Household Financial Wealth}

In measuring whether precautionary savings are sufficient — the “adequate financial safety net” of the ESI definition—-the ESI focuses on "liquid financial wealth," that is, wealth that can be easily accessed to replace lost income. In practice, this is all wealth holdings besides the primary home, personal vehicles, and earmarked retirement savings. In both versions of the index, we use data on wealth from the SIPP_-directly in the version of the index using the SIPP as the prime data source; and via imputation for the version using matched CPS data. In the latter case, we impute net liquid wealth based on total household income, total asset income (interest, dividends, and other property income), household size, and the age and race of the household head. ${ }^{26}$ Because the CPS measure of income includes retirement income distributions, we do not impute retirement wealth or augment incomes of retirees using an annuitized value of definedcontribution accounts as we do in the SIPP.

For computing typical recovery paths used to assess wealth adequacy, both the SIPP mini-panels and the two-year CPS "panels” are too short to track the development of incomes after a large income decline (hereafter, “recovery paths”). The PSID, however, permits the calculation of extended recovery paths. ${ }^{27}$ We calculate the median time until full recovery from an income drop of 25 percent or greater, for groups defined by the size of the income drop, pre-

\footnotetext{
${ }^{26}$ Our imputation process measures the group-specific probabilities of negative, zero, and positive net liquid wealth, and the mean and standard deviation of a transformation of wealth selected so that randomly sampling from this distribution produces a match between the distributions of observed and imputed wealth in the SIPP. In particular, we use the seventh root transformation of wealth, which is approximately normally distributed for both negative and positive values of wealth. We then re-create these group-specific distributions in the CPS.

${ }^{27}$ Because the PSID switched to biannual data collection after 1997, we use data from odd years only.
} 
drop income levels, and age. Finally, we calculate the average sum of the losses (the difference between pre-drop income and actual income) for each group, based on observations with median recovery length by group (4 to 16 years). Individuals whose incomes drop by 25 percent or more who have net financial wealth in excess of that amount for their characteristics (drop size, predrop income level, and age) are treated as secure.

Individuals frequently experience another large income loss during their recovery from a previous drop. We measure time from the first observed qualifying income loss—ignoring subsequent losses that would also count as a substantial drop along the way-to estimate duration in a recovery path. Individuals also often bounce back to their pre-drop income, but then experience further losses. The definition of "recovery" in the ESI counts someone as recovered as soon as they recover the first time to their pre-drop income, even if they later experience a drop that would undo that recovery.

\section{Accounting for Out-of-Pocket Medical Costs}

The challenges to estimating MOOP in a way consistent with the ESI's design are formidable. The CPS, like the SIPP sample on which the earlier ESI was based, does not include medical expenditure data necessary to calculate the reduction in available family income caused by MOOP over the 1986-2010 period. Thus, to impute MOOP expenditures, we use two donor datasets: The Consumer Expenditure Survey (CEX) and the SIPP. The CEX provides us with a long-running estimate of the relationship between medical spending and income, age, and family size. We use this dataset to generate imputed family-level MOOP for the first year in which each family appears in our dataset. The SIPP, by contrast, allows us to estimate the dynamics of medical spending over time. Thus, even when we use the March CPS as the source for data on 
year-to-year income changes, the SIPP continues to play a role as a donor file for wealth and MOOP dynamics imputations.

Our method of MOOP imputation is motivated by several observations:

1. When log-transformed, medical spending as a share of household income is approximately normally distributed.

2. The shape of the normal distribution varies by income and age.

3. Few families experience the average level of MOOP, and

4. There is extensive serial correlation in MOOP within families (in the SIPP), meaning that independently imputing two years statically (cross-sectionally) would overstate household resource volatility.

We therefore stochastically impute an estimate of MOOP as a proportion of income for year t-1 using the CEX. This model assigns households a level of MOOP as a proportion of income that is drawn from the observed distribution for that income and age group in the CEX (i.e., different households with the same characteristics can receive different values). We then model persistence of MOOP using SIPP data. This modeling relies on data from 1996 to 2005 in the SIPP. Reliable MOOP data are not available for the period prior to 1996 or between 2005 and 2009. This modeling accounts for changes in household composition and income. Because the distribution of MOOP relative to income has changed over time, this persistence imputation is calculated in ranks. That is, we rank households based on their proportion of income being spent on MOOP in year $\mathrm{t}-1$ and predict where in that household would rank in year $\mathrm{t}$ using the pattern observed in the SIPP (again, with a stochastic component). Using ranks to model persistence in this way allows us to respect changes over time in the level and dispersion of MOOP spending as 
occurs in the CEX data. Finally, we match these ranks to the ranked distribution of static imputed MOOP spending in year $t$. More detail is available in Hacker et al. (2011). ${ }^{28}$

\section{Results}

This section provides estimates of the ESI from 1985 through 2010 using the SIPP and for 1986 through 2010 using the CPS, as well as a more limited version of the index (focused on 25 percent or greater drops in household income) starting in 1969 using the PSID. In brief, the results from the ESI show that economic insecurity has increased substantially over the last generation, and especially in recent years; levels of insecurity-though elevated across the board-are much higher among those with limited education, as well as among racial minorities and younger workers; and the recent downturn is producing particularly deep losses.

\section{The Trajectory of the ESI}

The results from the ESI show that economic insecurity has increased substantially over the last generation, and especially in recent years. Figure 4 shows the results for both versions of the index; the discussion that follows focuses on the CPS-based version, which allows for an examination of the most recent downturn.

[Figure 4 Here]

In 1986, 14.3 percent of Americans experienced a major economic loss without sufficient resources to buffer that loss. During the recession of the early 1990s, this rose to 16.9 percent, and during the downturn of the early 2000s, it reached 18.8 percent. In recent years, economic

\footnotetext{
${ }^{28}$ Although the imputation is based on household-level characteristics, a random individual for each household is chosen to be the "donor" for the household. By selecting the same individual across years, rather than averaging within the household, we ensure that "bad" or "good" luck draws from the imputation do not get averaged out.
} 
insecurity has increased dramatically. In the three years from 2008 through 2010, the level of economic insecurity experienced by Americans consistently exceeded the level reached at any time during the past quarter century, with more than one in five of Americans experiencing a decline in available household income of 25 percent or greater in each of these years.

This substantial increase cannot simply be attributed to the recent economic crisis. Americans' level of economic security does fluctuate with the general health of the economy. For example, when the business cycle experiences an upturn, Americans' odds of suffering a large fall in income decrease. But this cyclical pattern has been accompanied by a gradual but steady rise in the overall prevalence of economic insecurity in good times as well as in bad. Indeed, the rise in insecurity during the mid-2000s outpaced that of the most recent recession. The most obvious explanation for this is that downward volatility is bounded for households given previous shocks. The most recent recession was accompanied by record median unemployment duration, and as of 2010 the labor market had not recovered in tandem with output (see figure 5). In a “jobless recovery”, experiencing large losses becomes more difficult with lower household income bases. In other words, consecutive losses become less likely than during a period of growth where joblessness may be shorter-term.

\section{[FIGURE 5 ABOUT HERE]}

During downturns, economic security has eroded, but between downturns, it has not bounced back to previous levels. The "new normal" in each subsequent economic cycle has featured a higher level of economic insecurity. This rise can be seen by comparing the ESI across "peaks" (or "troughs") in the business cycles. Or we can simply estimate the overall trend in the

level of the ESI. In Figure 6, we superimpose this estimated annual trend line for the 1986-2010 period (1985-2010 period for the SIPP-based estimates) over the results presented in Figure 4. 
This trend line shows that the share of Americans defined as insecure has increased by approximately 5.9 (4.9) percentage points over the 1986-2010 (1985-2010) period, or proportionally by about 40 (42) percent in the CPS (SIPP).

[Figure 6 Here]

Those who experience at least a one-quarter drop in their available income are also falling farther. In 1986, the typical (or “median”) loss for someone with an available income decline of at least 25 percent was 43 (39) percent in the CPS (SIPP). In 2010, it was 47 (43) percent. The increasing size of typical drops for those experiencing available income declines of 25 percent or larger addresses a potential concern with the ESI. It might be that the ESI is going up because more people are "just clearing” the 25 percent loss threshold. In fact, however, while a bigger share of Americans are exceeding this threshold, those who do so now typically experience slightly larger drops than did those who exceeded the threshold in the past.

\section{What Drove the ESI?}

The index simultaneously incorporates large income losses, changes in out-of-pocket medical spending, and wealth adequacy. Breaking the ESI down into its component parts shows that the rising chance of income loss, the growth of out-of-pocket medical spending, and the rise in household debt all contribute to the upward trend over the last generation (Figure 4). By contrast, the degree to which the ESI rises over time is reduced by taking into account the liquid financial wealth that some households have to cushion large losses. The largest contribution to both the level of the ESI and the upward trend-across both versions of the index-is the increasing chance of large drops in household income.

[Figure 7 Here] 
Looking at these components separately, the rising level of household financial debt (excluding home loans) has modestly contributed to the increasing ESI by reducing household's incomes after debt service and decreasing the share of those with adequate financial safety nets (see Figure 8). The families with the least financial assets have seen their standing fall precipitously, particularly among the bottom 10 percent, but also among the bottom 25 percent. Meanwhile, the typical financial wealth holding has hovered around zero over the 1986-2010 period. In other words, the majority of Americans over this period had no financial safety net. Below the highest wealth levels, financial wealth declined significantly during the recent recession, with the net financial wealth of households at the 10th percentile declining by roughly \$10,000 between 2004 and 2010.

[Figure 8 Here]

Turning to medical care, out-of-pocket medical costs have clearly come to represent a larger amount and share of the household budget. The median household spent around 36 percent more out of pocket in 2010 than did the typical household in 1986. During the most recent downturn, out-of-pocket spending as a share of income has continued to rise as households have lost workplace insurance coverage and family incomes have stagnated alongside rising medical costs. Figure 9 shows the share of Americans at different income levels spending more than a tenth of their income on out-of-pocket medical costs—a common measure of high spending. Aged Americans spend much more than younger Americans, and the share of older Americans spending 10 percent or more has risen across all income groups. Among younger Americans, by contrast, out-of-pocket costs as a share of income have risen sharply for middle-income groups, but the lowest-income Americans appear more insulated. One possible explanation is the expansion of Medicaid and the Children's Health Insurance Program, which has offset losses of 
health insurance coverage among moderate-income families. Another may be that low-income individuals are increasingly either putting off or failing to pay for care. ${ }^{29}$

[Figure 9 Here]

It is worth noting that MOOP spending's impact on the index is constrained for two reasons. First, because of data limitations in the CEX, our imputation procedure does not account for health insurance coverage. Second, our dynamic imputation model is based only on data from a short window in the SIPP (1996-2005). Health insurance coverage both buffers against MOOP spending shocks and has declined gradually over the course of our series. By using a model of MOOP spending dynamics that is based on the middle of the series, we likely overestimate the impact of MOOP spending prior to our SIPP measurement (1986-1995) and underestimate it in recent years (2006-2010), which would tend to lead us to understate the upward trend in instability of incomes less MOOP spending. ${ }^{30}$

Despite these limitations, it seems likely that the long-term trend toward insecurity stems primarily from the gradual but clear rise in the chance of individuals experiencing large declines in their household income. Since 1986, major drops in household income have become markedly more common. While this trend precedes the recent downturn, the last few years have witnessed a sustained elevation of family income instability that is unprecedented in the last generation.

\section{The Varied Experience of Economic Insecurity}

\footnotetext{
${ }^{29}$ Studies that have tracked different aspects of access over time reveal several patterns that might account for reduced or stable spending among the lowest income strata. Beginning in the mid-1990s, uninsured Americans (who are disproportionately from low-income households) began avoiding more expensive venues for medical care, such as hospital emergency departments. See Xu, Nelson, and Berk (2009). And in the past five years, there is emerging evidence that substantial out-of-pocket medical spending is deterring use of health services by members of lowerincome households, including children. See Cunningham and Felland (2008).

${ }^{30}$ Preliminary analysis of MOOP dynamics in the most recent SIPP panel from 2009 to 2010 indicates that this is indeed the case.
} 
During the recent recession, economic insecurity affected Americans of all backgrounds, reaching across lines of education, age, household type, and race. In nearly all major demographic groups, the ESI was significantly higher in the 1996-2007 period than it was in the 1986-1997 period, and significantly higher still in the aftermath of the downturn (2008-2010). ${ }^{31}$

Yet this common increase should not obscure the highly divergent experiences of economic insecurity, revealed by Table 1 . To begin with, the incidence of a major economic loss varies systematically by education. The differences are large: On average, 25.8 (24.2) percent of Americans in households headed by someone lacking a high-school degree suffered a major economic loss each year between 2008 and 2010, compared to 15.8 (13.5) percent of those in households headed by someone with post-college education in the CPS (SIPP). Insecurity by income group shows a similar disparity.

\section{[Table 1 Here]}

Levels of economic insecurity also vary across household types. Multiple-adult households without children and single individuals have the lowest level of insecurity; singleparent households, the highest. Notably, households with children in which at least two adults (almost always parents) are present experience a fairly high prevalence of large declines in available income, raising doubts about the common image of dual-earner families as insulated from economic insecurity.

Another relevant basis of comparison is age. Older Americans are often thought to be relatively immune from major economic threats, given the strong role of Social Security and the virtually universal health insurance provided through Medicare. The ESI suggests otherwise.

\footnotetext{
${ }^{31}$ A series of tests were conducted to assess whether differences across demographic groups and over time were statistically significant and with only a few trivial exceptions, all groups are statistically distinct from each other. For further details, see the Technical Report (Hacker et al. 2011).
} 
While older Americans are indeed less likely to experience large income losses than younger Americans, large medical spending burdens substantially offset their advantage with regard to income stability. Nonetheless, young adults (18-34) are by far the most insecure age group during the 2008-2010 period, with nearly one in four experiencing losses in available income of 25 percent or greater without an adequate financial safety net each year.

Turning to race and ethnicity, African Americans and Hispanics stand out as uniquely vulnerable to economic insecurity as captured by the ESI. Historically, African-Americans have experienced slightly higher levels of insecurity than Hispanics. During the downturn, however, the ESI for Hispanics rose much more quickly than that for African Americans, so that during 2008-2010, both groups experienced comparably—and strikingly—high levels of economic insecurity. On average during those years, 25.8 percent of African Americans and 26 percent of Hispanics had losses in available income of one quarter or more and lacked an adequate financial safety net to cushion those declines.

\section{Comparing Results with the PSID}

The PSID has been following a representative sample of U.S. families and their split-offs since the late 1960s, as well as a discrete low-income sample known as the Survey of Economic Opportunity (SEO) sample. In 1996, the PSID discontinued the SEO sample (a small group of families were subsequently re-incorporated, but they do not have national weights and are not included in the analyses to come). The PSID also enlarged the representative sample to incorporate post-1968 immigrant groups, and switched to a biennial survey procedure.

Despite its long time span, the PSID was not used for the construction of the ESI for several reasons. First, because of the move to a biennial structure, the PSID does not allow for 
year-to-year analysis of income losses after 1996. Although the post-1996 survey asks about income in the "off year," the quality of off-year reports is low, and the question was discontinued in the most recent survey. ${ }^{32}$ Second, the PSID data on medical spending is available only after 1999 and only at the level of two years of aggregate spending. Finally, and most important, its sample sizes are much smaller, which precludes reliable analyses of demographic sub-groups.

The PSID is a family-level dataset, and its definition of families differs from the definition of "household" used in other income datasets, such as the SIPP and the March Current Population Survey. To simplify, in the PSID families are people living together and related by blood, marriage, or adoption, as well as long-term cohabiters. Multiple families may live in a household. There are relatively small differences between estimates at the household level and those at the family level, but the distinction should be kept in mind when comparing PSID results with findings from other datasets.

The PSID-based ESI analyses look at individuals' household income (adjusted for family size)—which includes all sources of cash income before taxes, including earnings, asset income, government monetary benefits, private cash transfers, and business income but does not include lump-sum and one-time sources of income, such as inheritances and retirement distributions. The sample includes the representative and SEO samples. All results are weighted using individual weights that account for the oversampling of low-income respondents as well as attrition from the beginning of the PSID to the present.

Because it has been conducted only once every two years since 1996, the only way to look at income loss after 1996 is to compare income in one year to income two years later, rather than from one year to the next. Partly for this reason, the PSID shows a higher proportion of Americans experiencing 25 percent or greater income drops than does the SIPP, although the

\footnotetext{
${ }^{32}$ Andreski, Stafford, and Yeung (2008).
} 
trends match relatively well during the overlapping years. ${ }^{33}$ (Neither of these series excludes large income drops coincident with retirement.)

[Figure 10 Here]

As Figure 10 shows, the share of individuals experiencing drops of 25 percent or greater from one year to two years later has risen substantially: From 1969 to 2004, the incidence almost doubled. The upward movements correspond to cyclical downturns, but the series do not decline noticeably during the extended expansion of the 1990s. ${ }^{34}$ The PSID results indicate, therefore, that the prevalence of large income losses rose between the late 1960s and mid-1980s and continued to rise in subsequent years as they did in the CPS and SIPP. ${ }^{35}$

\section{Implications}

The ESI is designed to fill a gap in existing theoretical and empirical analyses of economic security by providing a simple integrated measure of economic security grounded in panel data on economic status. Prior research has focused primarily on individual sources of economic insecurity, such as earnings volatility and the incidence of large medical expenditures. The ESI, by contrast, incorporates several key factors—income declines, medical spending shocks, and financial wealth buffers—into a single unified measure. We have shown that this measure can be calculated using several datasets—-the Survey of Income and Program Participation, the Current Population Survey, and, in a more limited form, the Panel Study of

\footnotetext{
${ }^{33}$ We end the PSID series in 1993, because of data issues mentioned in the appendix associated with the PSID's transition to a new survey design.

${ }^{34}$ However, the spike in large income drops during the early to mid-1990s must be viewed with some suspicion due to its coincidence with major administrative changes in the PSID during this period. For most of the PSID's history, the income reports in the PSID closely match those in other respected datasets, including the Census Bureau's Current Population Survey (CPS). However, the PSID departs from the CPS at the bottom of the income distribution for roughly five years in the mid-1990s. During this time, the lowest income categories in the PSID have lower average incomes than seen in other datasets and the overall variance of the PSID income data jumps. Nonetheless, even excluding the early to mid-1990s data from consideration, there is a clear upward trend in large income losses. ${ }^{35}$ Dynan (2010).
} 
Income Dynamics — and that the level of the ESI and its upward trend over the last generation is robust to these alternatives.

The ESI is an index of the objective experience of individuals, rather than of their subjective perceptions. Nonetheless, the ESI is designed to embody reasonable judgments about how a typical American would respond to the risks that it tracks. Indeed, its development was importantly aided by survey data specifically collected for this purpose. These polls show that a majority of Americans believe a 25 percent decline in income will cause them hardship, and believe that job loss and large medical costs are among the most threatening risks to household economic well-being and among the most difficult to anticipate and prepare for.

The ESI shows that Americans are not only facing greater insecurity than at any time within a generation, but also that they were at heightened risk even before the recent downturn. It also provides a new means of examining the sources of insecurity and the degree to which Americans with different characteristics are vulnerable to it. To provide an ongoing measure of American economic security, the ESI will be updated on a regular basis as new data become available.

Though the ESI was constructed to provide a reliable indicator of economic security consistent with the twin goals of rigor and accessibility, it is by no means an exhaustive measure, and further research is needed to augment and complement it. For example, while the ESI accounts for medical spending, it does not capture other expenses that might be considered nondiscretionary, such as the expenses required to earn income through working (including child-care costs). Examining their impact on fluctuations in available household income would be a natural extension of the ESI. 
Similarly, the ESI also does not capture changes in the risk that individuals will lack adequate retirement income (though other measures of this risk exist and suggest it has increased over time). ${ }^{36}$ The main conceptual obstacle to the incorporation of this risk into the ESI is the need to measure the risk of inadequate retirement income on a comparable basis or scale with the risk of large short-term large losses in available income. It is worth noting, however, that the ESI's treatment of earmarked retirement wealth as unavailable for buffering current income losses incorporates the idea that individuals need to save for retirement and that using retirement savings for current consumption jeopardizes future security.

It is also important to recognize that the ESI measure of medical spending risk has some limitations. First, the focus on out-of-pocket spending (including premiums) means that those who go without necessary medical care or insurance may look more secure than they really are. ${ }^{37}$ Second, the ESI also largely ignores the effects of elevated levels of out-of-pocket medical spending that persist across multiple years, focusing instead on annual changes. Third, and cutting the other way, the ESI does not account for the ways in which Americans' medical care has become more sophisticated and efficacious, even if more expensive.

Another area where further research would be fruitful is the impact of wealth changes on economic security. Although the ESI brings wealth holdings into the calculation of individuals' and households' economic security, it does not directly capture the gains or losses that families experience as a result of fluctuations in wealth. Indeed, it is unclear how to treat wealth fluctuations in a way that is comparable to income declines, because fluctuations in wealth do not directly affect well-being until the underlying assets are sold (except via the effect on income

\footnotetext{
${ }^{36}$ See in particular Alicia Munnell's work at the Center for Retirement Research at Boston College, http://crr.bc.edu/director/alicia_h._munnell_2.html, and work at the Michigan Retirement Research Consortium, such as Kezdi and Sevak (2004).
} 
from assets, which we do measure). Wealth losses are relevant for the ESI only if, in the absence of wealth losses, assets would be liquidated to counteract losses in available income. While the ESI captures the crucial buffering function of wealth (relying on imputations), an improved understanding of the intertwined effects of income and wealth changes on economic security is a worthy goal for future research.

Another research priority is to gain a better understanding of what exactly causes the large income declines reflected in the ESI. To what extent are these causes voluntary (such as planned withdrawal from the labor force to care for children) or involuntary (such as job loss due to layoff or income declines due to real wage or hours cuts)? To answer this question precisely requires more detailed analyses of the factors associated with income loss.

Pending these analyses, the most that can be said is that the losses measured by the ESI appear to be primarily involuntary: First, the ESI rises and falls with the unemployment rate, suggesting a very central role for unemployment, much of which is involuntary. Second, by excluding those who accumulate sufficient stocks of financial wealth before an income decline, the ESI treats as secure the individuals whose income losses are most obviously voluntarynamely those who build up financial assets so they can take time off from work. Third, while the ESI has risen at varying rates across different demographic groups, it has risen significantly across all of them. If its rise was driven by one set of voluntary behaviors, such as exit of one parent from the labor force for child-rearing in two-parent families, then the rise in income losses would be expected to be concentrated among those able or most likely to engage in such behaviors. As the last section indicated, this is not the pattern. Instead, the ESI indicates an increase in the incidence of large income losses across all subgroups, though to a varying degree. Finally, there is suggestive evidence that earnings volatility is shaped more by changes in 
earnings than hours (Dynan, 2010) and that consumption and income volatility have risen in tandem (Gorbachev, 2011), both of which suggest a fundamental role for involuntary income changes.

More important, there is good reason to believe that more sharply distinguishing between involuntary and voluntary declines would only affect the level of the index, not trends in it. With regard to the trend in the ESI over time, the crucial concern is whether the mix of voluntary and involuntary causes has changed. Although, again, a definitive answer awaits additional research based on the ESI and other sources, there are few reasons to think that the mix of voluntary and involuntary causes has substantially changed since the mid-1980s. ${ }^{38}$ The most likely candidate for a major shift — an increase in the probability of families having two earners, one of whom cycles in and out of the labor force to have or raise children-cannot, for example, be driving the results outside of two-parent families with children.

Ultimately, no single measure can capture all aspects of economic security. But the ESI represents a tool for capturing some of the most important aspects. It provides a baseline for researchers to expand the concept of economic security beyond its existing scope, which is defined by relatively narrow aspects of well-being. It also provides a tool for those interested in identifying which segments of American society are least secure and why. And it provides a framework for evaluating the effects of public and private policies among these vulnerable groups and Americans as a whole.

\footnotetext{
${ }^{38}$ See, for example, Dynan (2010, p.3-6), in which the author reports "voluntary choices are not the dominant force behind increasing household income volatility.”
} 


\section{References}

Agell, J., “On the Benefits from Rigid Labour Markets: Norms, Market Failures, and Social Insurance,” Economic Journal, 109(453), 143-164, 1999.

Andreski, P, F. Stafford, and W. Yeung, “Assessing the PSID t-2 Income Data,” PSID Technical Paper Series \#08-06, 2008. http://psidonline.isr.umich.edu/Guide/Quality/PSID\%20t2\%20report.pdf.

Attewell, P., “The Impact of Family on Job Displacement and Recovery,” Annals of the American Academy of Political and Social Science, 562, 66-82, 1999.

Bénabou, R, and E. Ok, “Social Mobility and the Demand for Redistribution: The POUM Hypothesis,” Quarterly Journal of Economics, 119, 447-487, 2001.

Burtless, G., and S. Siegel, "Medical Spending, Health Insurance, and Measurement of American Poverty,” Washington, DC: The Brookings Institution, 2001. www.brookings.edu/reports/2001/08useconomics_burtless.aspx.

Carroll, C., K. Dynan, and S. Krane, “Unemployment Risk and Precautionary Wealth: Evidence from Households' Balance Sheets,” The Review of Economics and Statistics, 85(3), 586604, 2003.

Citro, C., R. Michael, eds., Measuring Poverty: A New Approach, Washington, DC: The National Academies Press, 1995.

Collins, S., J. Kriss, M. Doty, and S. Rustgi, Losing Ground: How the Loss of Adequate Health Insurance Is Burdening Working Families, New York: Commonwealth Fund, 2008.

Congressional Budget Office (CBO). "Recent Trends in the Variability of Individual Earnings and Household Income.” Washington, DC: CBO, 2008. 
Cunningham, P., and L. Felland, “Falling Behind: Americans’ Access to Medical Care Deteriorates, 2003-2007,” Center for Health System Change Tracking Report No. 19, 2008.

Cusack, T., T. Iversen, and P. Rehm, "Risks at Work: The Demand and Supply Sides of Government Redistribution,” Oxford Review Economic Policy 22(3), 365-389, 2006.

Dickens, W., "Differences Between Risk Premiums in Union and Nonunion Wages and the Case for Occupational Safety Regulation,” The American Economic Review, 74(2), 320-323, 1984.

Edin, K., and L. Lein, Making Ends Meet: How Single Mothers Survive Welfare and Low-Wage Work, New York: Russell Sage Foundation, 1997.

Davis, S., “The Decline of Job Loss and Why It Matters,” University of Chicago, NBER and AEI, prepared for the ASSA Meetings in New Orleans, 2008.

Dynan, K., "The Income Roller Coaster: Rising Income Volatility and Its Implications,” Washington, DC: Brookings Institution, 2010. www.brookings.edu/articles/2010/0401_income_volatility_dynan.aspx.

- and D. Kohn, The Rise in U.S. Household Indebtedness: Causes and Consequences, Discussion Paper, 2007-37,Finance and Economics Discussion Series, Divisions of Research \& Statistics and Monetary Affairs, Federal Reserve Board (Washington, DC), 2007.

- D. Elmendorf, and D. Sichel, “The Evolution of Household Income Volatility,” Washington, DC: The Brookings Institution, 2008. [.http://www.brookings.edu/papers/2008/02_us_economics_elmendorf.aspx]]. 
Diener, E., R Lucas, and C. Napa Scollon, "Beyond the Hedonic Treadmill: Revising the Adaptation Theory of Well-Being,” American Psychologist 51, 305-314, 2006.

Expert Group on Household Income Statistics.The Canberra Group.Final Report and Recommendations.Ottawa, 2001.http://www.lisproject.org/links/canbaccess.htm.

Fellner, G. and Sutter, M., “Causes, Consequences, and Cures of Myopic Loss Aversion: An Experimentatal Investigation,” The Economic Journal, Vol. 119(537): 900-916, 2009.

Gorbachev, O., “Did household consumption become more volatile?” The American Economic Review, 101(5): 2248-70, 2011

Gottschalk, P. and R. Moffitt, “The Rising Instability of US Earnings,” Journal of Economic Perspectives, 26(4), 3-24, 2009.

Graham, C., and S. Pettinato, Happiness and Hardship: Opportunity and Insecurity in New Market Economies, Washington, DC: The Brookings Institution Press, 2002.

Gruber, J., “The Wealth of the Unemployed,” Industrial and Labor Relations Review 55(1), 7994, 2001.

Hacker, J., The Great Risk Shift: The New Economic Insecurity and the Decline of the American Dream, rev. and exp. ed., New York: Oxford University Press, 2008.

- $\quad$ G. Huber, P. Rehm, M. Schlesinger, and R. Valletta. Economic Security at Risk: Findings from the Economic Security Index, 2010. http://www.economicsecurityindex.org.

- $\quad$ P. Rehm, and M. Schlesinger, Standing on Shaky Ground: Americans’ Experiences with Economic Insecurity, 2010.http://www.economicsecurityindex.org.

- P. Rehm, and M. Schlesinger. 2013. “The Insecure American: Economic Experiences and Policy Attitudes amid the Great Recession.” Perspectives on Politics (March).

- $\quad$ G. Huber, A. Nichols, P. Rehm, and S. Craig, The Technical Appendix for the Economic Insecurity and the Great Recession, 2011. 
[http://economicsecurityindex.org/upload/media/ESI_Technical_Suppplement_revised.pd f]

Jacobs, E., and J. Hacker, “The Rising Instability of American Family Incomes, 1969-2004,” Washington, DC: Economic Policy Institute, 2008. [http://www.epi.org/publication/bp213/].

Japelli, T., and L. Pistaferri, “The Consumption Response to Income Changes,” Annual Review of Economics 2, 2010.

Kahneman, D., J. Knetsch, and R. Thaler, “Anomalies: The Endowment Effect, Loss Aversion, and Status Quo Bias,” Journal of Economic Perceptions 5(1), 193-206, 1991.

Kahneman, D., A. Tversky, "Prospect Theory: An Analysis of Decision under Risk," Econometrica, Vol. 47(2): 263-292, 1979.

Kezdi, G and P. Sevak, "Economic Adjustment of Recent Retirees to Adverse Wealth Shocks.” MRRC WP 75, 2004. [http://mrrc.isr.umich.edu/publications/papers/pdf/wp075.pdf]

Kusnet, D., L. Mishel, and R. Teixeira, Talking Past Each Other: What Everyday Americans Really Think (and Elites Don’t Get) About the Economy, Washington, DC.: Economic Policy Institute, 2006.

Ligon, E., and L. Schechter, “Measuring Vulnerability,” Economic Journal 113(486), C95-C102, 2003.

Lusardi, A., D. Schneider, and P. Tufano, "Financially Fragile Households: Evidence and Implications.” National Bureau of Economic Research Working Paper Series No. 17072, 2011. http://www.nber.org/papers/w17072 
Michalos, A., P. Hatch, D. Hemingway, L. Lavallee, A. Hogan, and B. Christensen, "Health and Quality of Life of Older People, a Replication After Six Years,” Social Indicators Research, Springer Science \& Business Media B.V., 2007.

Miron-Shatz, T., “Am I Going to Be Happy and Financially Stable? How American Women Feel When They Think About Financial Security,” Judgment and Decision Making 4(1), 102112, 2009.

Mughan, A. and D. Lacy, “Economic Performance, Job Insecurity and Electoral Choice,” British Journal of Political Science 32(3), 513-553, 2002.

Nichols, A., Trends in Income Inequality, Volatility, and Mobility Risk: Via Intertemporal Variability Decompositions. Washington, DC: The Urban Institute, 2008. [www.urban.org/UploadedPDF/411799_income_trends.pdf].

- $\quad$ and M. Favreault, The Impact of Changing Earnings Volatility on Retirement Wealth, Washington, DC: Urban Institute, 2009.

Osberg, L., and A. Sharpe. “How Should We Measure The 'Economic’ Aspects Of WellBeing?” Review of Income and Wealth, 51(2), 311-336, 2005.

Quartz, S., “Reason, Emotion and Decision-Making: Risk and Reward Computation with Feeling,” Trends in Cognitive Sciences. Vol. 13(5): 209-215, 2009.

Rehm, P., “Risks and Redistribution: An Individual-Level Analysis,”Comparative Political Studies 42(7), 855-881, 2009.

Rehm, Philipp, Jacob S. Hacker, and Mark Schlesinger. 2012. “Insecure Alliances: Risk, Inequality, and Support for the Welfare State.” American Political Science Review 106(2): 386-406.

Slovic, P. The Perception of Risk. London: Earthscan Publications, Ltd., 2000. 
Stephens, M., “The Long-Run Consumption Effects of Earnings Shocks,” The Review of Economics and Statistics, 83(1), 28-36, 2001.

Sunstein, C., "Probability Neglect: Emotions, Worst Cases and the Law,” Yale Law Journal, 112(1): 61-107, 2002.

Melvin Stephens, “Worker Displacement and the Added Worker Effect,” Journal of Labor Economics 20, no. 3 (2002):504-537.

Liliana Winkelman and Ranier Winkelman, "Why Are the Unemployed So Unhappy? Evidence from Panel Data,” Economica, 65, 1-151, 1998.

Xu, K., B. Nelson, and S. Berk, “The Changing Profile of Patients Who Used Emergency Department Services in the United States: 1996 to 2005,” Annals of Emergency Medicine 54(6), 805-810, 2009. 
Figure 1: Impact of equivalizing income on the ESI

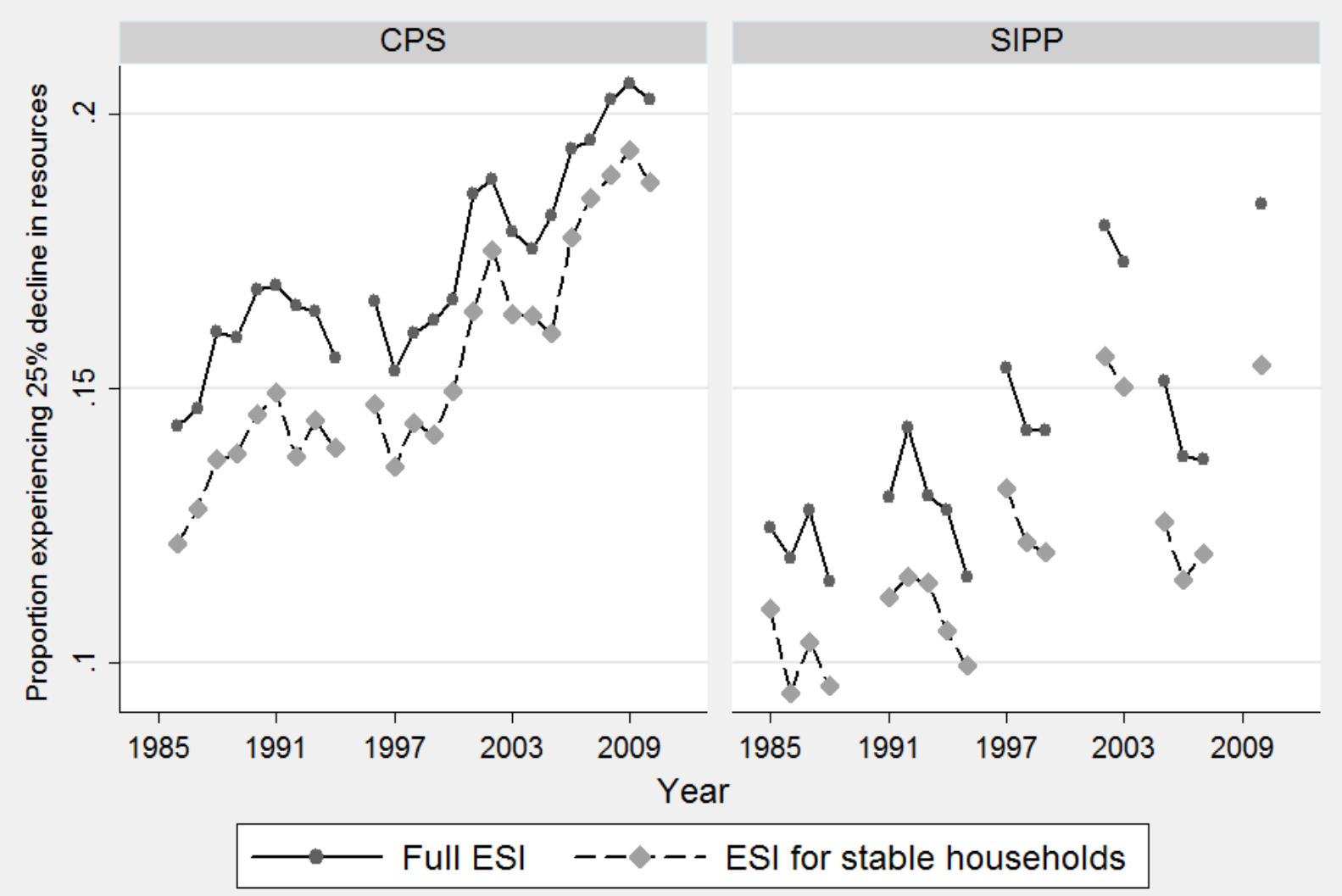

Graphs by source 
Figure 2: Impact of retirement exclusion on the ESI

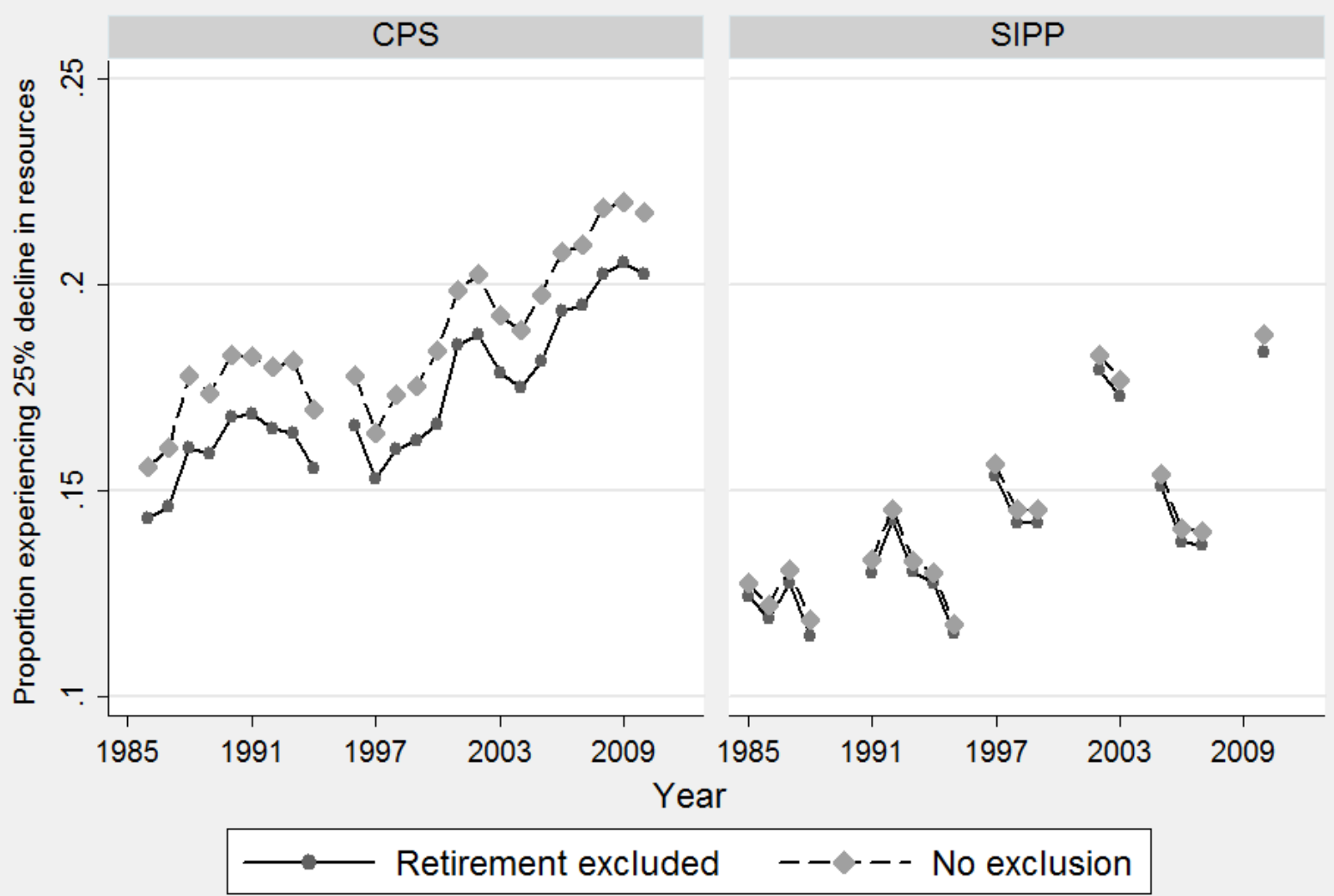

Graphs by source 
Figure 3: Imputation rates by survey and type

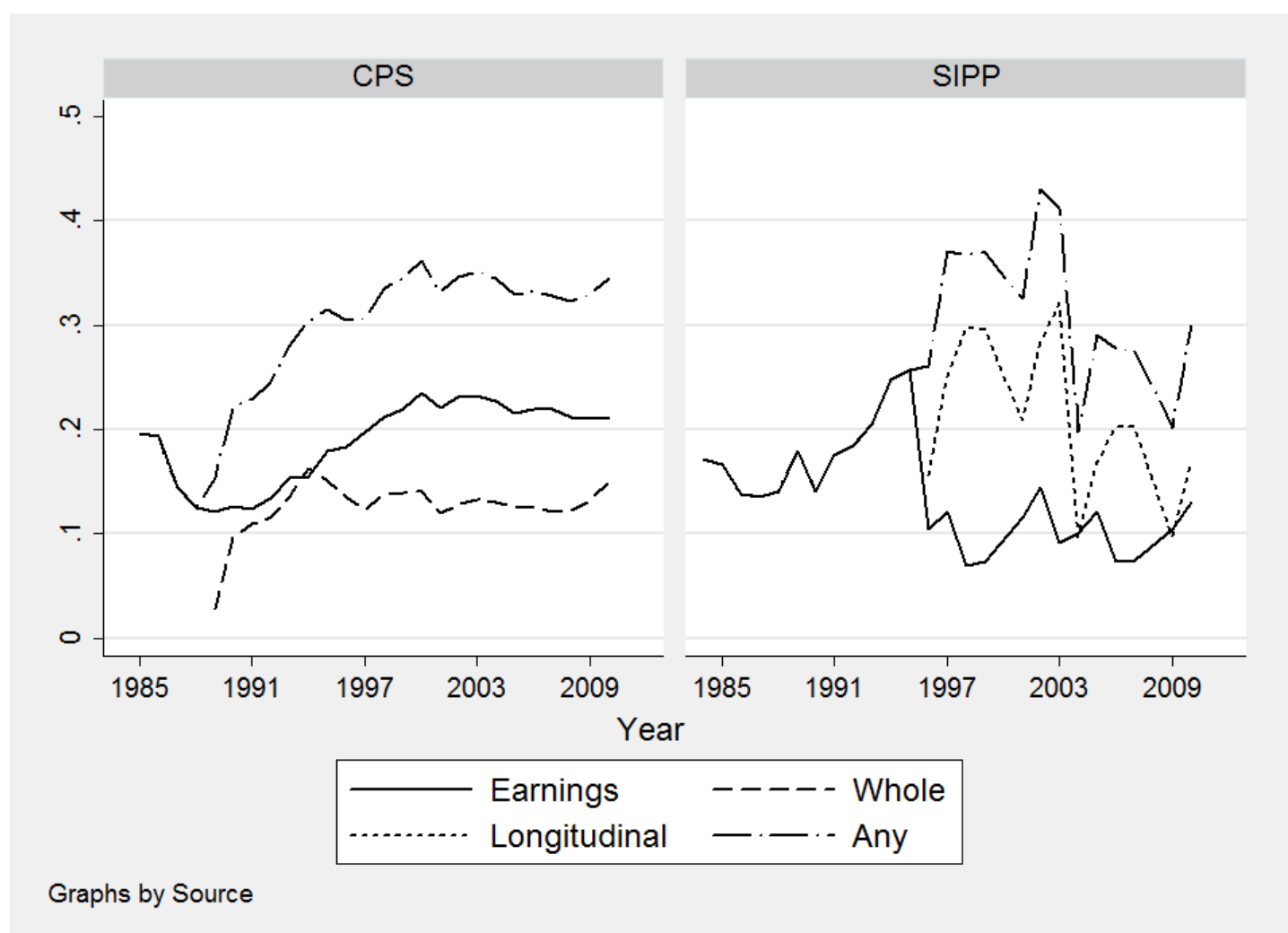


Figure 4: ESI series by survey

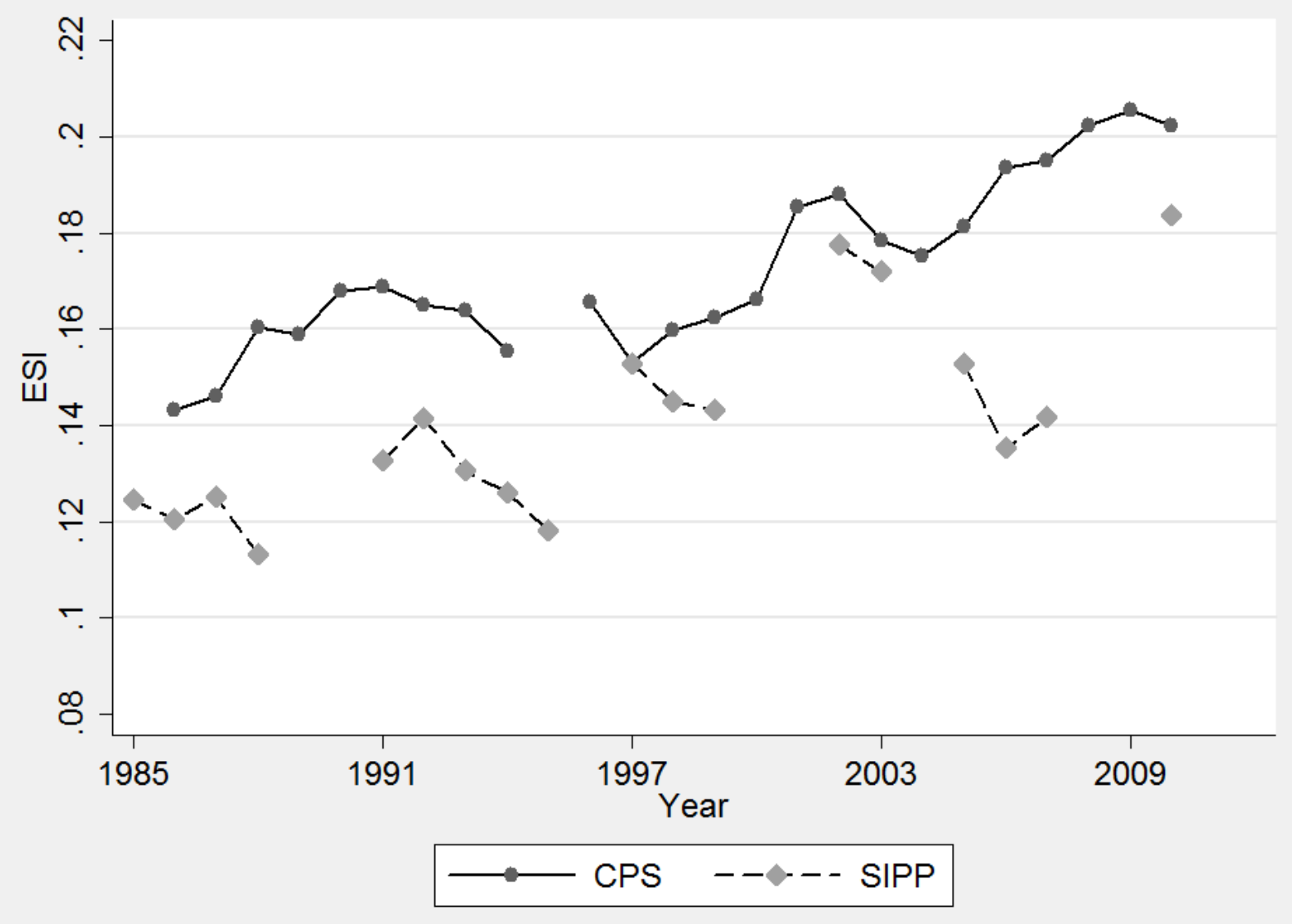


Figure 5: Median unemployment duration (1967-2010)

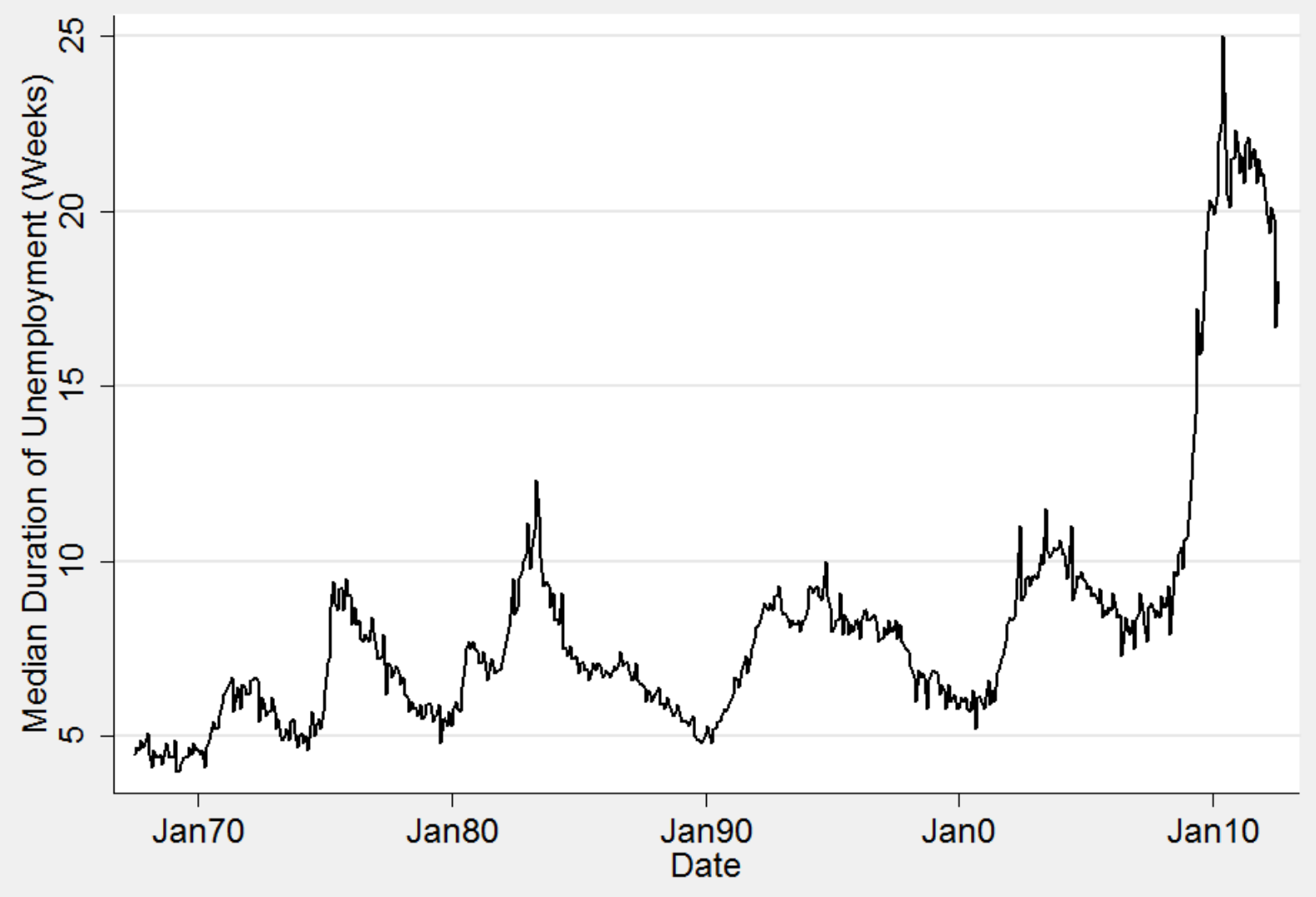

Source: FRED 
Figure 6: ESI trend by survey

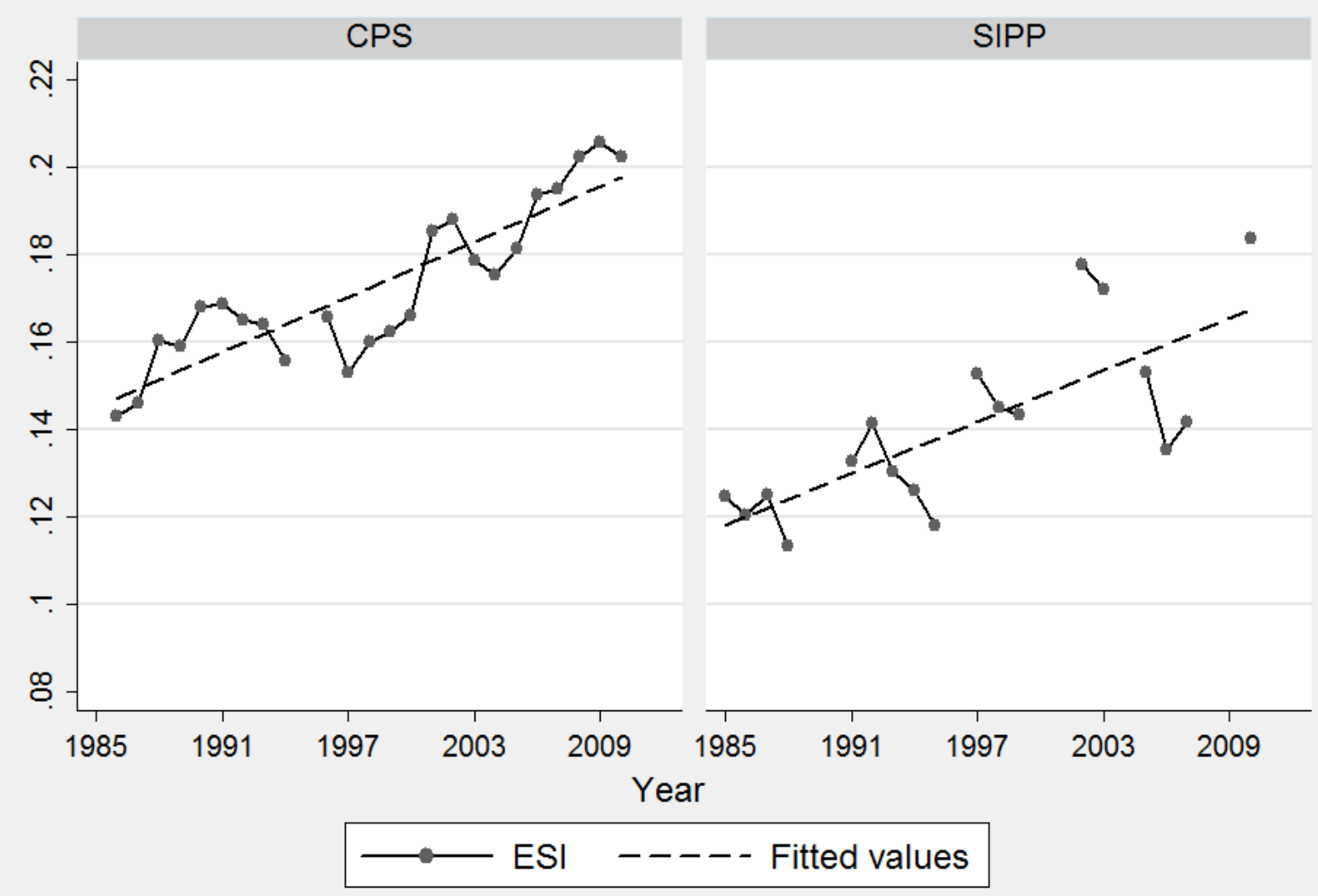

Graphs by source 
Figure 7: The contribution of income, medical costs, debt and wealth by survey 7a. Source: CPS (with SIPP, CEX, and PSID)

\section{CPS}

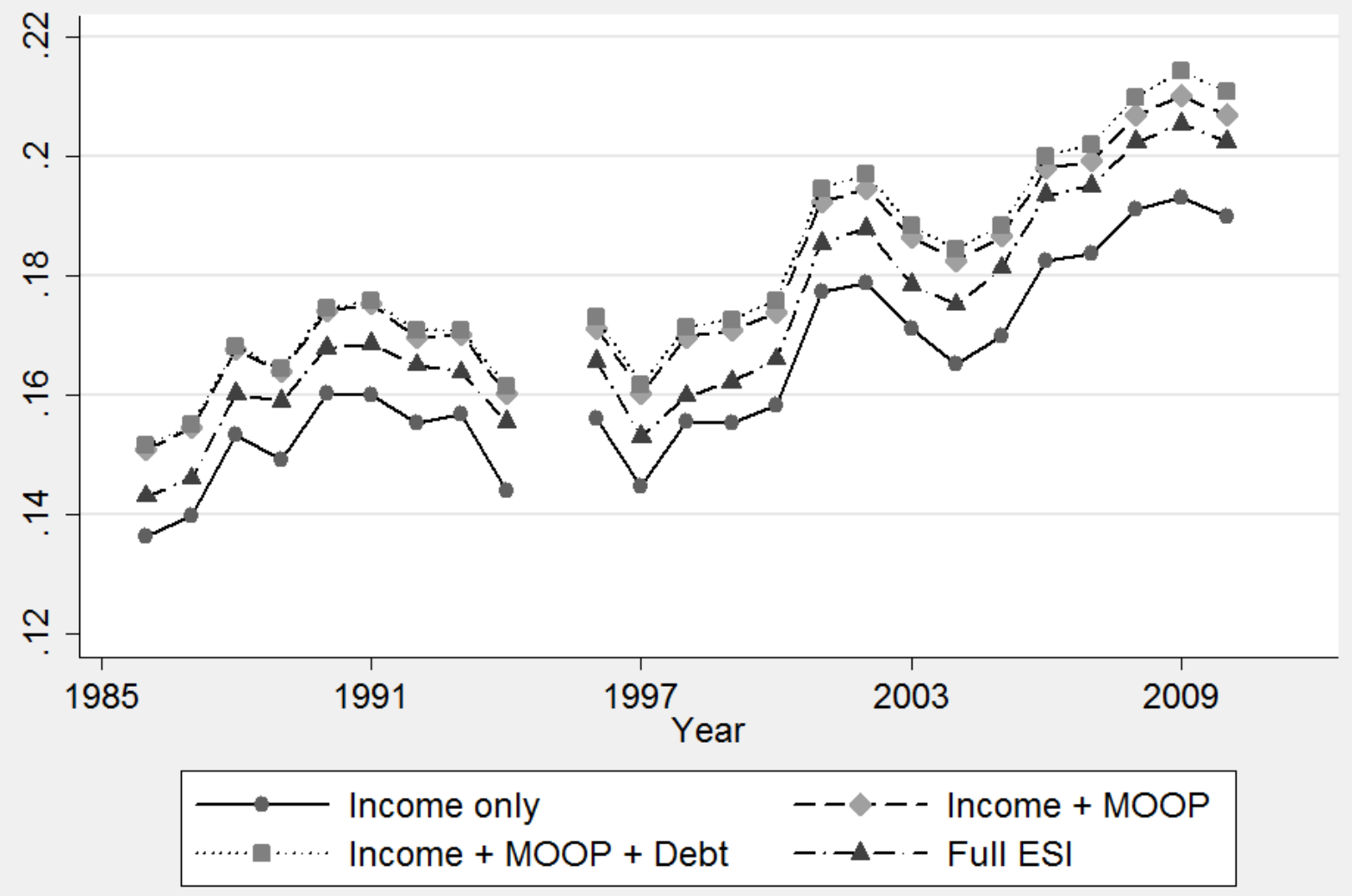


7b. Source: SIPP (with CEX and PSID)

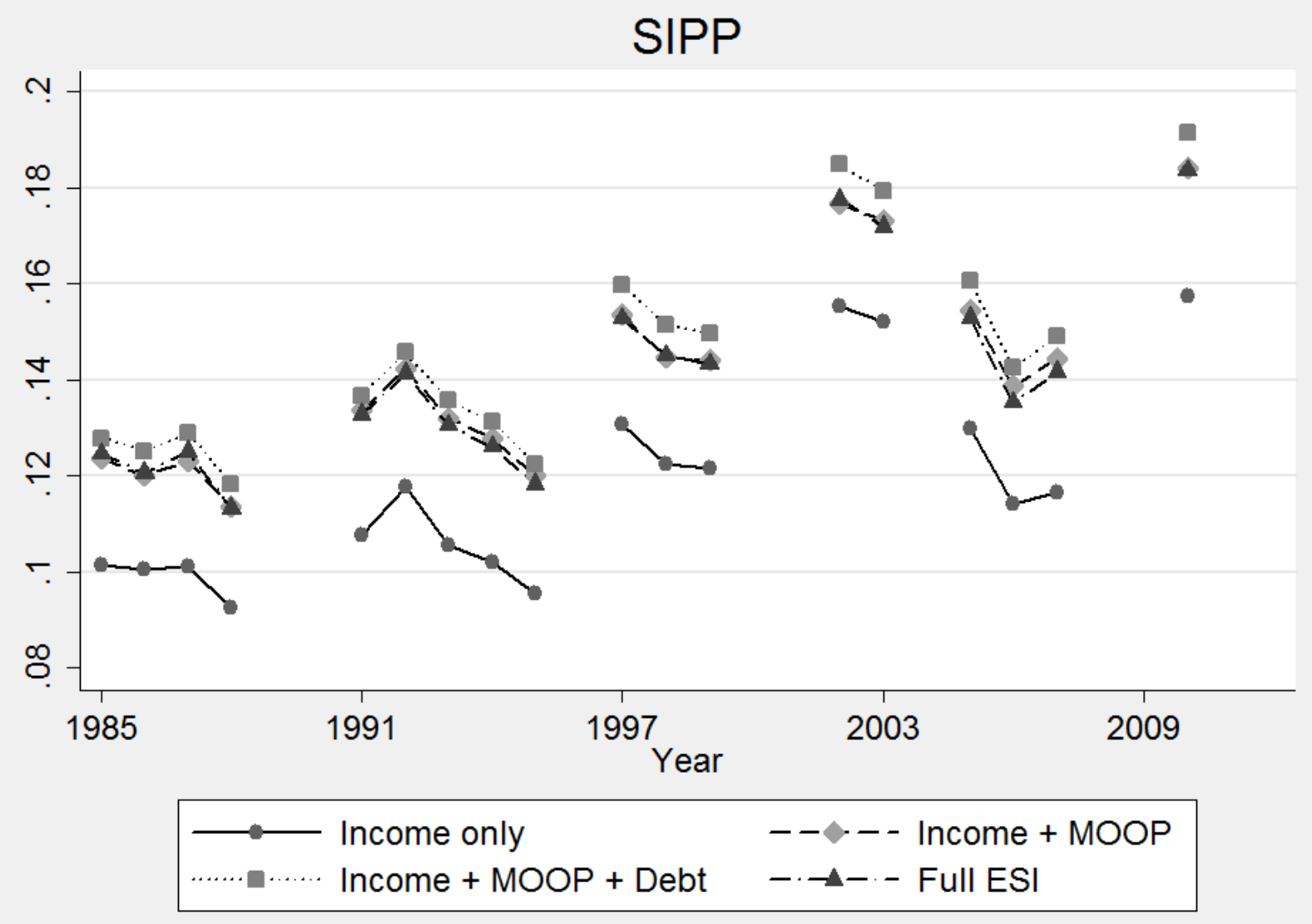


Figure 8: Financial wealth holdings at the median, $25^{\text {th }}$ percentile and $10^{\text {th }}$ percentile of wealth holders (in 2010 USD)

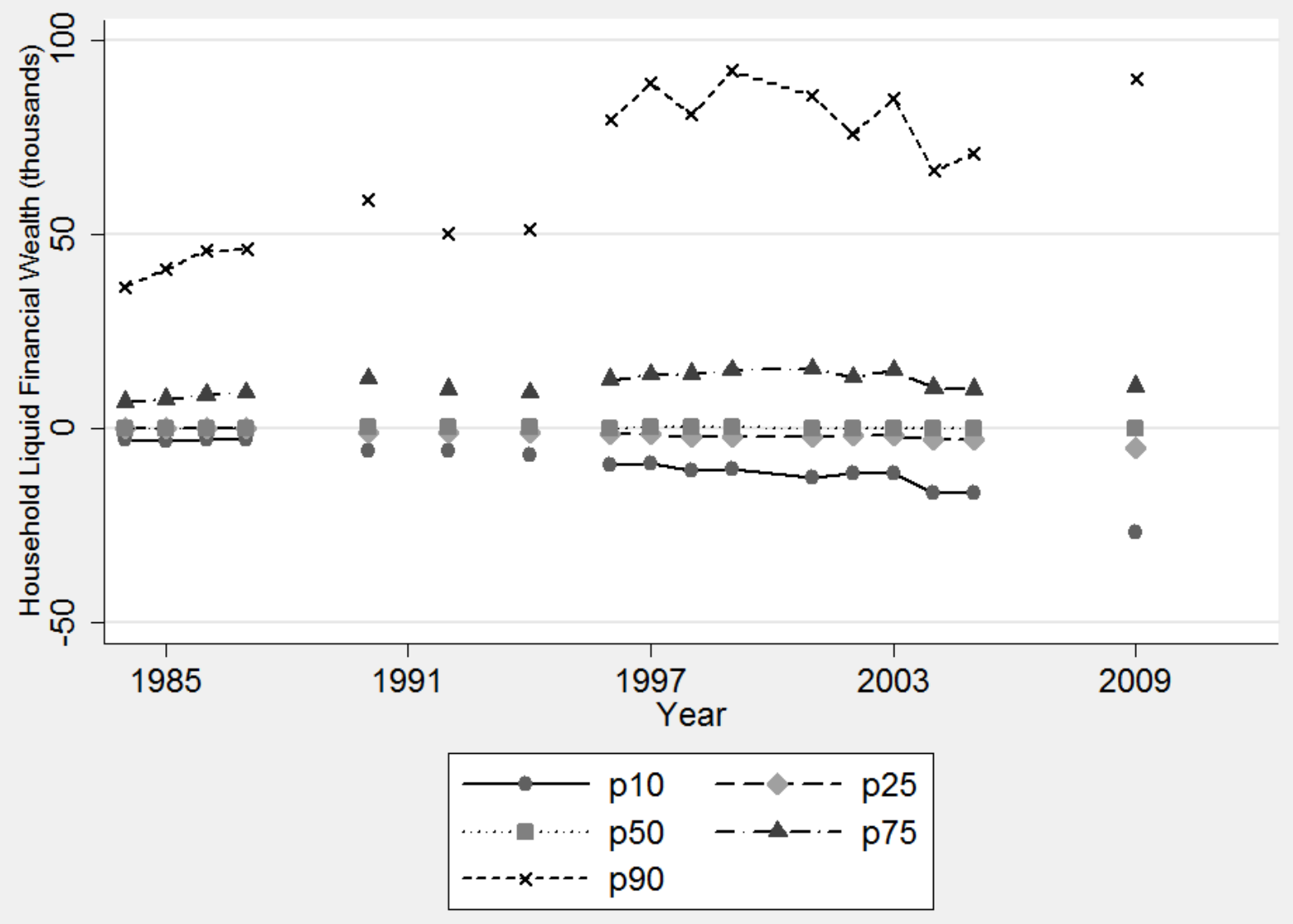

Source: SIPP 
Figure 9: Share spending more than 10 percent of income on medical care, by income and age

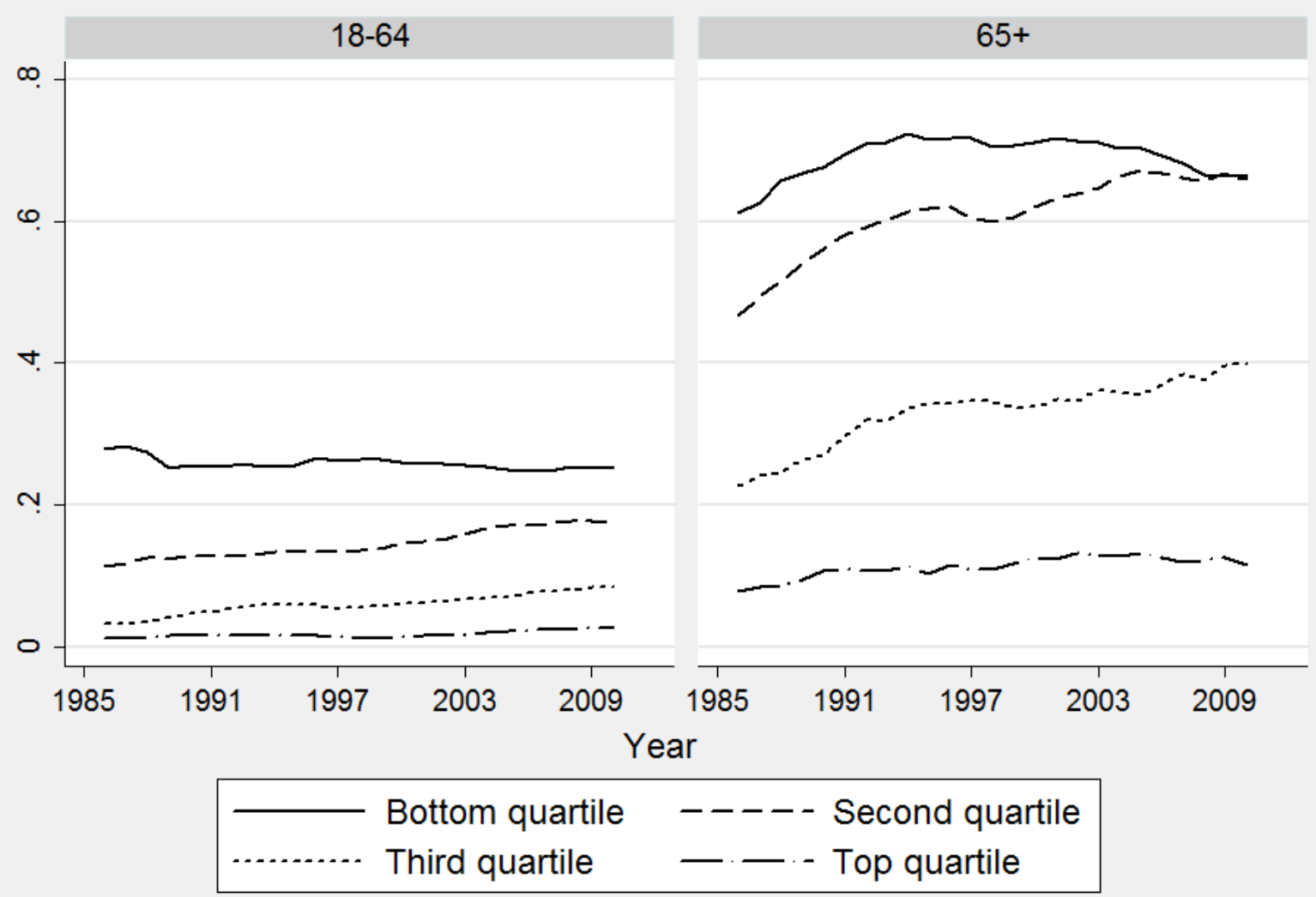

Graphs by agecat

Source: CEX 
Figure 10: Prevalence of 25 percent drops across surveys (income only)

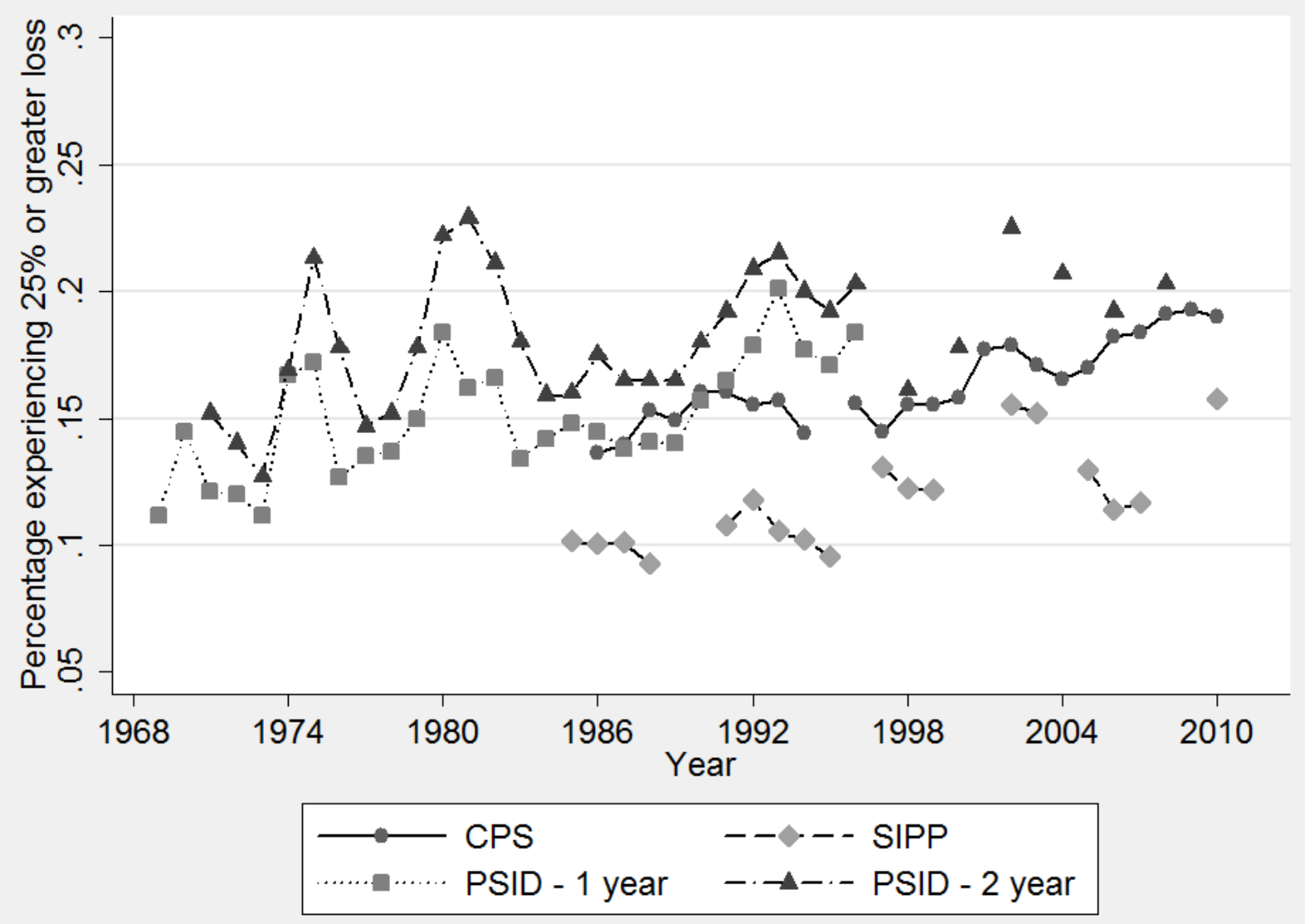

Source: CPS, SIPP, PSID 
Table 1: Prevalence of large economic losses by demographic groups

\begin{tabular}{|c|c|c|c|c|}
\hline Education & & $\begin{array}{l}1985- \\
1996\end{array}$ & $\begin{array}{l}1997- \\
2007\end{array}$ & $\begin{array}{l}2008- \\
2010\end{array}$ \\
\hline \multirow[t]{2}{*}{ Less Than High School } & CPS & 0.1973888 & 0.2288381 & 0.258101 \\
\hline & SIPP & 0.1519703 & 0.1854642 & 0.2421355 \\
\hline \multirow[t]{2}{*}{ High School Grad } & CPS & 0.1625695 & 0.1804317 & 0.2127695 \\
\hline & SIPP & 0.1269964 & 0.1597344 & 0.1980007 \\
\hline \multirow[t]{2}{*}{ Some College } & CPS & 0.1572816 & 0.1734813 & 0.2135148 \\
\hline & SIPP & 0.1222749 & 0.1472234 & 0.1881014 \\
\hline \multirow[t]{2}{*}{ College Degree } & CPS & 0.1302682 & 0.1552601 & 0.1819046 \\
\hline & SIPP & 0.1001887 & 0.1339547 & 0.155808 \\
\hline \multirow[t]{2}{*}{ Post-College } & CPS & 0.1213259 & 0.1436915 & 0.1578728 \\
\hline & SIPP & 0.0954122 & 0.1337835 & 0.1349078 \\
\hline \multicolumn{5}{|l|}{ Household Type } \\
\hline \multirow[t]{2}{*}{ Several adults with kids } & CPS & 0.1542142 & 0.1732942 & 0.2069058 \\
\hline & SIPP & 0.1227159 & 0.1482616 & 0.1894174 \\
\hline \multirow[t]{2}{*}{ Several adults without kids } & CPS & 0.1477326 & 0.1653952 & 0.1914963 \\
\hline & SIPP & 0.1228568 & 0.1537014 & 0.1779701 \\
\hline \multirow[t]{2}{*}{ Single individual } & CPS & 0.1628317 & 0.1773869 & 0.1938518 \\
\hline & SIPP & 0.1238538 & 0.1362593 & 0.1550517 \\
\hline \multirow[t]{2}{*}{ Single parent } & CPS & 0.2489192 & 0.2570604 & 0.2780799 \\
\hline & SIPP & 0.1669121 & 0.2095407 & 0.2563697 \\
\hline \multicolumn{5}{|l|}{ Race } \\
\hline \multirow[t]{2}{*}{ White } & CPS & 0.1436572 & 0.1602527 & 0.1846315 \\
\hline & SIPP & 0.1188522 & 0.141689 & 0.1669879 \\
\hline \multirow[t]{2}{*}{ Black } & CPS & 0.2151016 & 0.2263988 & 0.2487005 \\
\hline & SIPP & 0.1595973 & 0.188997 & 0.2136522 \\
\hline \multirow[t]{2}{*}{ Hispanic } & CPS & 0.210301 & 0.2077025 & 0.2465862 \\
\hline & SIPP & 0.1594842 & 0.1737451 & 0.2340482 \\
\hline \multicolumn{5}{|l|}{ Income } \\
\hline \multirow[t]{2}{*}{ Bottom quintile } & CPS & 0.236918 & 0.2457373 & 0.284802 \\
\hline & SIPP & 0.1857976 & 0.2126516 & 0.2539642 \\
\hline \multirow[t]{2}{*}{ Second quintile } & CPS & 0.1779645 & 0.2010486 & 0.2216038 \\
\hline & SIPP & 0.1418118 & 0.1745443 & 0.2212857 \\
\hline \multirow[t]{2}{*}{ Third quintile } & CPS & 0.1420723 & 0.1523104 & 0.1950011 \\
\hline & SIPP & 0.1125858 & 0.13626 & 0.1812581 \\
\hline \multirow[t]{2}{*}{ Fourth quintile } & CPS & 0.1143461 & 0.1278062 & 0.151676 \\
\hline & SIPP & 0.0979076 & 0.1196003 & 0.1407671 \\
\hline \multirow[t]{2}{*}{ Top quintile } & CPS & 0.1220434 & 0.1504954 & 0.1651614 \\
\hline & SIPP & 0.0946158 & 0.1200714 & 0.1300344 \\
\hline
\end{tabular}

